\title{
An approach to implement STEP-NC in the footwear industry
}

José-Francisco Gómez-Hernández ${ }^{a}$, Miguel Davia-Aracila ${ }^{a}$ José-Luis Sanchez-Romero ${ }^{\text {b }}$, Antonio Jimeno-Morenilla ${ }^{b}$

a INESCOP - Spanish Footwear Technology Centre, b Department of Computer Technology, University of Alicante

\section{A R T I CLE INF O}

\section{Keywords:}

Step-NC

Footwear

Machining

$\mathrm{CNC}$

$\mathrm{CAD} / \mathrm{CAM}$

Smart factories

Industry 4.0

\begin{abstract}
A B S T R A C T
There is a growing need to automate the footwear industry by introducing new methods and tools to improve footwear production. The use of CAD tools for the design of shoes and their components is increasingly common, but it is a sector in permanent adaptation to socio-economic changes where it is therefore complicated to incorporate high-tech machinery. The introduction of improvements in production is a necessity, so the use of technologies that allow the adaptation of old machinery with the latest technologies in the area of CAD/CAM would be an important advantage for the sector.

So far, each component is designed and manufactured separately. In this way, the real dependence that exists between the different components required for manufacturing footwear means that a change in any of these elements implies a redesign (CAD level) of the rest of the elements. This fact increases the manufacturing cost. It is also necessary to modify the way of manufacturing the product (CAM level), which is a complex manual process in many cases. The introduction of changes in an industrial environment with limited resources means a very slow implementation.

In this paper, a platform based on STEP-NC is defined to show the advantages that its implementation in footwear sector would imply, by relating all the elements involved in footwear manufacturing: CAD tools that generate the geometries of the components, CAM tools that define the paths for their machining, and the different machines that manufacture these components. Furthermore, additional advantages would be incorporated, such as process control, supervision, inspection, allowing information to flow in all directions.
\end{abstract}

\section{Introduction}

Traditionally, in the field of footwear manufacturing software, it has been usual to find different CAD/CAM applications that use different formats for storing and processing information. Most footwear applications have the possibility to export information in some standard format that allows interconnection with other applications. With regard to machines that produce most of the different parts that make up a shoe, the problem is similar, but in this case, there is usually no export or exchange module. The data has to reach the machine in a format that it can understand, and this code is usually different from the one used by a similar machine from another vendor.

To achieve this communication, applications often use different formats, usually plain text, representing different geometric objects; from files containing point clouds or polylines, to more complex and structured files such as those following the DXF, STL, IGES or STEP format. In the same way, there are also files containing machining information.

With the rise of the trend known as Industry 4.0, the interconnection of different systems and the needs to include, increasingly, complementary information in the integrated manufacturing process, there is a need to find a format that facilitates this process.

The STEP-NC [1], [2] standard is a powerful tool for the integrated management of the intercommunication of the different subsystems involved in the manufacturing process. This standard allows the exchange of information in a simple way. STEP-NC (ISO 10303 ap238 [3], [4] and ISO 14649 [5]) is based on the STEP standard (ISO 10303) as a geometrical basis, to which machining related extensions have been added. This format allows the incorporation of geometrical information, machining information and other types of information such as comments or indications. It also allows bidirectionality between design (CAD), machining (CAM) and manufacturing (CNC). With the appropriate extensions, this standard can also include process planning information (CAPP) [6], which means that it cannot only contain information about design or machining, but also about how the manufacturing process is to be done. It could also include information for inspection (closed-loop inspection) [7] thus controlling the whole manufacturing process.

The aim of this paper is to make a model for the use of the STEP-NC standard as a tool to interconnect all the sub-systems needed in the footwear industry, from the design of models to the manufacture of the shoes, on the basis that the interconnection between the design software and the NC machines is a requirement for smart factories and the communication must be bidirectional. Section 2 provides a background about standards in footwear industry. Section 3 explains the main features of STEP-NC. Section 4 shows the main features that STEP-NC should cope with in footwear manufacturing. Section 5 introduces an approach to integrate STEP-NC in the footwear industry. Section 6 shows an experimental test in the use of STEP-NC to mechanize a last and 
a heel, and finally, Section 7 summarizes the contributions of the research work.

\section{Research background}

The first machining systems began to appear in the 1960s. These systems had small programs to make different parts, but they were rigid and proprietary systems. Some of them even used punch cards to be programmed.

Later, the Electronic Industry Association began the development of a format that in 1980 would become the RS274D standard (ISO 6983), known as G-Codes [8]. It is based on preparatory $G$ functions (G0-G99), alternative $M$ (or machine) functions, axis movement commands (X, Y, Z, A, B, C), F (Feed rate) and S (Spindle Speed) commands, as well as T tool and $\mathrm{N}$ block identification commands. This system is widespread, but has some shortcomings:

- It focuses on programming the tool path with respect to the axes (instead of a machining task with respect to a part). It describes how the machining is to be done, not what to do. It is focused on the movement of the machine axis using a specific tool, but it does not define if the operation is performing a roughing or a finishing operation, neither indicates the milling strategy.

- The standard defines the syntax, but in many cases, it produces ambiguous semantics.

- Each manufacturer complements the standard according to their own needs, since the standard does not contemplate them (and this is why the files are usually not portable).

- A specific post-processor is needed for each machine.

- The flow of information is unidirectional (from design to manufacturing) and makes it impossible to feedback possible changes required from the manufacturing phase.

- At machine level, it is very difficult to control the path execution, and it is very complicated to change it.

- The data of the part to be machined are not available on the machine, which makes the verification and simulation tasks very difficult or even impossible.

G-Codes is deeply rooted, both in the way workers conceive the manufacturing process, and in the structure and architecture of the machines.

In 1992, the Electronics Industries Association introduced EIA-494 Basic Control Language (BCL), defined as a language that was portable and independent of the machine, but did not contain any model information [9], [10].

In 1999, Function Blocks (IEC-61499) for distributed industrial processes and control systems appeared. It is based on explicit events by the model and finite state automatons. Each function block encapsulates certain machining tasks (roughing a face, finishing a hole, drilling). One block function can encapsulate others to make more complex functions. Each machine implements its own way of performing each block function, adjusting to its characteristics. This means that the result can be different on two different machines. Basic block functions are defined, which are executed as an atomic unit [11]. A flow of events is also defined, which may be complex and supports a bidirectional information flow between the machining and design phases. This system has not been widely used.

In parallel, many machine manufacturers have developed their own language as an alternative to G-Codes. For example, Heidenhain uses both G-Codes and its own language called "Conversational Language"[12].

STEP-NC, on which the proposal of this paper is focused, starts in 1999 to complete the STEP format (which was initially designed to improve IGES, offering a neutral data exchange method), adding machining information to the geometry data provided by STEP. The machining information describes tasks at a high level with respect to geometry [1].

In 2004, through a European project, a standard called ShoeML was developed [13]. In this format many of the needs of the footwear manufacturing industry were expressed, especially in the definition of geometries. XML was used to store geometrical information, but in the machining stage it only concerned the cutting tables. This format is still used although by very few manufacturers, as most systems use proprietary formats.

\section{STEP-NC, the standard}

In 1999 a project called STEP-NC was started by the European group ESPRIT and was continued in 2001 as an international project, IMS STEP-NC, finally giving rise to ISO14649 where a model for CNC controls was defined; its aim was to replace ISO 6983. Later on, the CNC model was integrated into STEP (ISO10303) to produce ISO10303 ap238. It uses STEP to define the geometry and complements it with machining data. STEP-NC describes what to do at a high level, through tasks: pre-drilling, drilling, roughing, fine tuning, ... It presents the following advantages:

- $\quad$ Easily defined tasks.

- Self-documenting, contains CAD and CAM information.

- It eliminates the use of machine-specific post processors.

- It is safer and more adaptable as it is independent of the machine vendor.

- It provides a complete and structured data model, associated with geometry and technical information, therefore, no information is lost throughout the various stages of the process.

- Changes in the production stage can be stored, providing two-way feedback between design and manufacturing.

- Object-oriented vision.

- XML files can be used, allowing electronic exchange.

STEP-NC is being implemented in many sectors, which take the standard definition and customize or adjust it for their specific characteristics. Sectors such as the automotive or aeronautical industries are directly involved in the development of STEP-NC, taking direct advantage of the benefits that this technology is introducing. Similarly, STEP-NC has been developed to be used on machines such as machining centres and lathes. For its use on other types of machines, the standard follows a continuous process of updating. 
The current trend in the CAD field is to use the STEP format as an exchange format for geometry files; if CAM information is also required, it is strongly recommended to use STEP-NC. A few years ago it was very common to use the IGES format (Initial Graphics Exchange Specification) for the exchange of geometric information (there was no machining information), but since the birth of STEP in 1994, all interest in continuing to develop IGES was lost (the last version was published in 1996). Therefore, the initial idea of STEP-NC to replace IGES is being fulfilled. In addition, STEP-NC meets the needs of incorporating machining information.

As reference, STEP-NC can be used in CNC milling machines [14], 3D printers [15], machining robots [16], [17], CAMs [18], circular sawblades [19], ...

\section{STEP-NC in the footwear sector}

The footwear manufacturing sector has its own characteristics, among which it is worth mentioning that it is very traditional and conservative. When technology was first introduced in this sector, it had to provide a complete $\mathrm{CAD}+\mathrm{CAM}+\mathrm{Machine}$ solution. In this way, most systems were closed systems. For instance, with regard to last manufacturing, the manufacturers of lathes limit the input to their own format (although internally they usually use standard numerical controls slightly customized) and you just can use the lathe with their proprietary format, generated by themselves. In heel and sole manufacturing, machining centres or CNC milling machines are often used. In this case, most machines use GCodes for their operation, but each one has customized the standard according to its needs. The manufacture of patterns and pieces is carried out on computer-controlled cutting tables, where the format casuistry is very varied, from DXF formats (ASCII to represent the points) and simple instructions to raise/lower the head, to more complex languages, such as HPGL, developed by HP for the control of plotters. Other machines use their own format, as most of the machines have been modified to support shoe production, allowing support to produce right/left-handed parts (mirroring the component) and sorting to produce different shoe sizes.

The footwear sector is undergoing a change with the arrival of Industry 4.0 since, on the one hand, large footwear productions are being made in emerging countries and, on the other hand, firms specialized in quality footwear are betting on short production and customized footwear. This trend demands a strong control, both in the design and manufacturing phases, requiring a lot of investment in software (CAD/CAM) as well as in machinery. This investment is expensive, so the trend is to use machines capable of machining different components. For example, robots could be used to machine different parts of a shoe: lasts, heels, insoles, and even allow the manipulation of different components. In this process of change, the need for a manufacturing oriented language is emerging, so that it is not only independent of the type of machine for which it is intended, but also allows for the incorporation of additional information, two-way communication between design and machining, as well as geometric references that facilitate subsequent verification. At the same time, new machines and devices are bursting into this classic sector: 3D printers, digitizers, virtual reality devices, and so on.

Since the standard allows for the integration of geometry, machining and complementary information in the same document, a proposal will be made considering the specific needs of the footwear sector.

To make a complete shoe (see Fig 1), and following the complete process from scratch, the digitized foot of the person, or a standard model, would be needed. From this foot model, and especially if the foot has special or abnormal characteristics, a custom-made last would have to be designed, as well as an insole if any pathological condition of that foot has to be corrected. In addition, a sole would be needed for the shoe, as well as the different pieces and linings that will form the shoe. If it is necessary to manufacture customized footwear, it would only be required to add the data related to customization (digitized foot, measurements, etc.) from the preceding proposal. Otherwise, the information would be the same: last, insole, sole, upper parts and linings, information on the grading, sizes, etc.

With this data, all the geometric information needed to start the manufacturing process would be available. Based on these geometries, it would be necessary to decide how to manufacture them. In the CAM section, the way the different components are going to be machined would be determined.

The shoe last would be manufactured on a CNC lathe. A machining centre (CNC) would be used to manufacture the insole, the heel/sole, or its moulds. The uppers and the lining would be machined on a cutting table. During the shoe manufacturing process, many different machines are used, and many of them need information on the shoe geometry to make the appropriate toolpath.

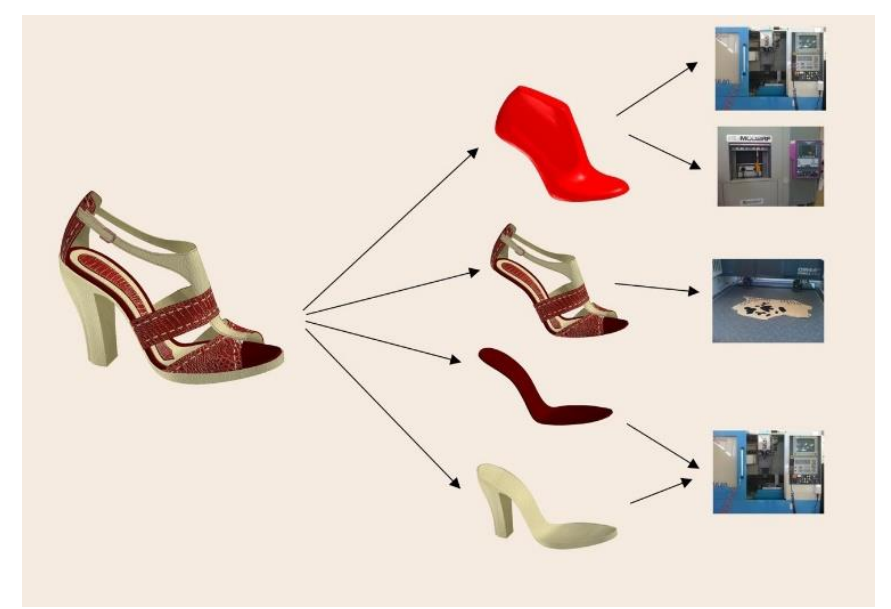

Fig 1: A shoe, its components and where it is manufactured

Once the strategies for machining each of the different geometries have been defined, the resulting file would be sent to the machine. It would generate the path following the instructions indicated in the CAM specifications. When operating the machine, the worker can access all the information and, if necessary, complement or modify it. For example, if the specific tool indicated in the CAM is not available, a similar tool could be used and produce the same result. The strategy parameters could also be modified dynamically; for example, if the operator observes, during machining, that the tool is suffering from a high stress level because the step is too large, he could adjust the parameter and set the step as required. If this could not be done, the machine would have to be stopped, the strategy parameters would have to be edited in the CAM, the machining file would have to be generated again, sent to the machine and started again. 
It is very common that during the manufacturing process of the complete shoe, or after the prototyping, the shoe last may change to solve a design problem or to make the shoe more comfortable. The complete shoe depends on the last, so all the different parts and components need to be updated.

On the other hand, the information that accompanies all the geometry may be very important. Let's imagine that, when including the information of the digitized foot, the person who scanned it could add comments indicating that a particular area of the foot has to be discharged. This information will be used by the designer of the insole, but it will also be available to the worker who has to manufacture it.

In STEP-NC, the path itself is optional (as opposed to Gcodes, where it is essential) and therefore the numerical controls need to be able to generate this path. In many cases, this means taking the machining calculation process from the CAM stage computer to the machine. Therefore, in order to use the STEPNC standard and take advantage of its benefits, all machines would have to be updated, since they would need a higher level of intelligence and autonomy.

Considering that the footwear sector is particularly sensitive to socio-economic and regulatory changes, which very often occur in relatively short periods of time, updating machinery to take advantage of the novelties provided by these new technological solutions is a very important investment over the years.

It is not common to find machines compatible with STEP$\mathrm{NC}$, and although this format is beginning to be available in some modern machining centres, the price of a machine of this type is very high, making the entry of these modern systems difficult and with more advantages in a sector where renovation is not easy or frequent.
Analysing all this information, it can be seen that the introduction of STEP-NC in this sector is going to be a necessity in the next few years, and that changing the machinery to support all this information would require a quite important investment. An alternative would be to adapt the machinery that companies currently have, so that they can operate and use the advantages of STEP-NC.

This adaptation can go through several phases. Initially, a computer connected directly to the machine could be employed to use the information received in STEP-NC format, calculate the machining tool path (if only the strategy is defined) and generate a file compatible with the machine. A dedicated hardware device may be used to calculate the path, but cloud computing may also be used to do it [20], [21]. As a final part, a retrofitting of the current machines with a new control that supports STEP-NC could be carried out. This would require converting a "dumb" control, only capable of following a list of points, into a control capable of understanding geometry, and since the file would indicate what to do, it would have to calculate the path and decide how to move it to machine and obtain the correct result. This means that the control has to be smart and, therefore, it will require much more computing power.

\subsection{A review of the current machine features}

In order to evaluate the proposal from an economic point of view, an initial study has been carried out on the environment to which the proposed solution would be targeted. Specifically, the $\mathrm{CAD} / \mathrm{CAM} / \mathrm{CNC}$ solutions of several companies in the sector have been analysed in order to assess whether the viability of the proposal is realistic.

\begin{tabular}{|c|c|c|c|c|}
\hline Machine & Picture & Toolpath & Format & Step-NC compatible \\
\hline $\begin{array}{l}\text { Leather cutting } \\
\text { machine }\end{array}$ & & & $\begin{array}{l}\text { DXF, HPGL, ... } \\
\text { Normally open } \\
\text { format }\end{array}$ & $\mathrm{NO}$ \\
\hline 3 axis $\mathrm{CNC}$ & & & $\begin{array}{l}\text { G-code } \\
\text { Open }\end{array}$ & NO \\
\hline Lathe (lasts) & & & $\begin{array}{c}\text { FRV } \\
\text { Proprietary format }\end{array}$ & $\mathrm{NO}$ \\
\hline Sewing machine & & & Proprietary format & NO \\
\hline
\end{tabular}




\begin{tabular}{|l|l|l|l|}
\hline $\begin{array}{l}\text { Pounding \& roughing } \\
\text { machine }\end{array}$ & Proprietary format & NO \\
\hline 3D printer & & $\begin{array}{c}\text { G-code } \\
\text { Open }\end{array}$ & NO \\
\hline
\end{tabular}

Table 1: Different machines used in footwear production

As can be seen in Table 1, some of the machines used to manufacture different components of a shoe are shown. Each of them uses a different format and most of them use proprietary formats, none of them being compatible with the Step-NC standard.

\subsection{Used geometries and toolpaths in footwear CAD/CAM software}

Although this study focuses on the machining part, it should not be forgotten that the CAD information for each of the different parts/pieces that make up a shoe, and which are used for its manufacture, must also be included. For this purpose, the main parts and components used for their manufacture are analysed, as well as the way in which they are represented in the STEP-NC.

Shoemakers start the shoe design with a foot model of the population. In the case of an orthopaedic shoe, a prescription will also be issued by a podiatrist or a similar professional.

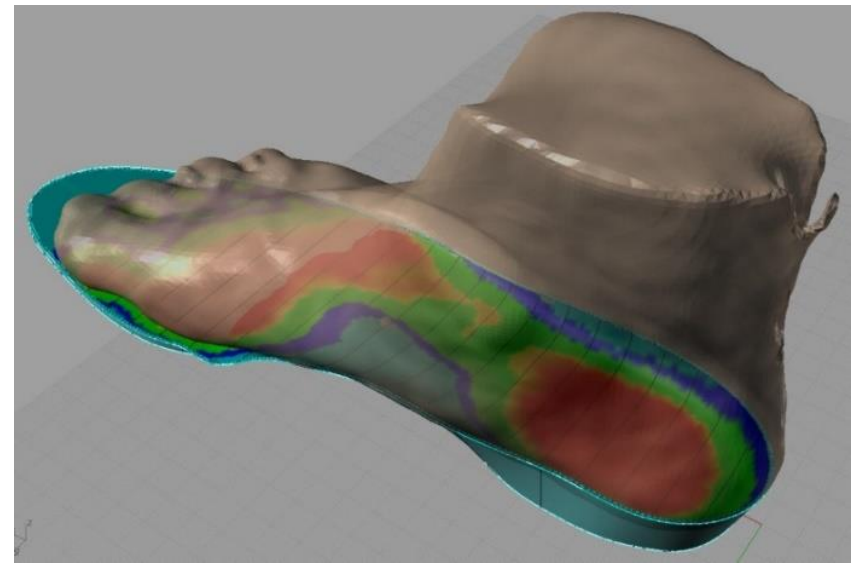

Fig 2: Foot, plantar pressures map and insole

From this information, a last will be fit to this foot (see Fig 3) [22]. With the last, the foot, the plantar pressures map and the prescription of a specialist if necessary, the insole will be designed (see Fig 2).
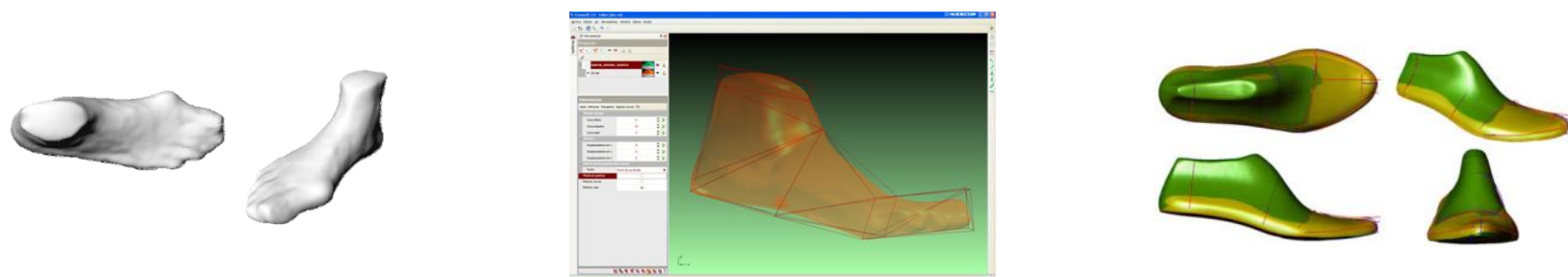

Fig 3: Digitized foot, adjusting the last to the foot and the result 


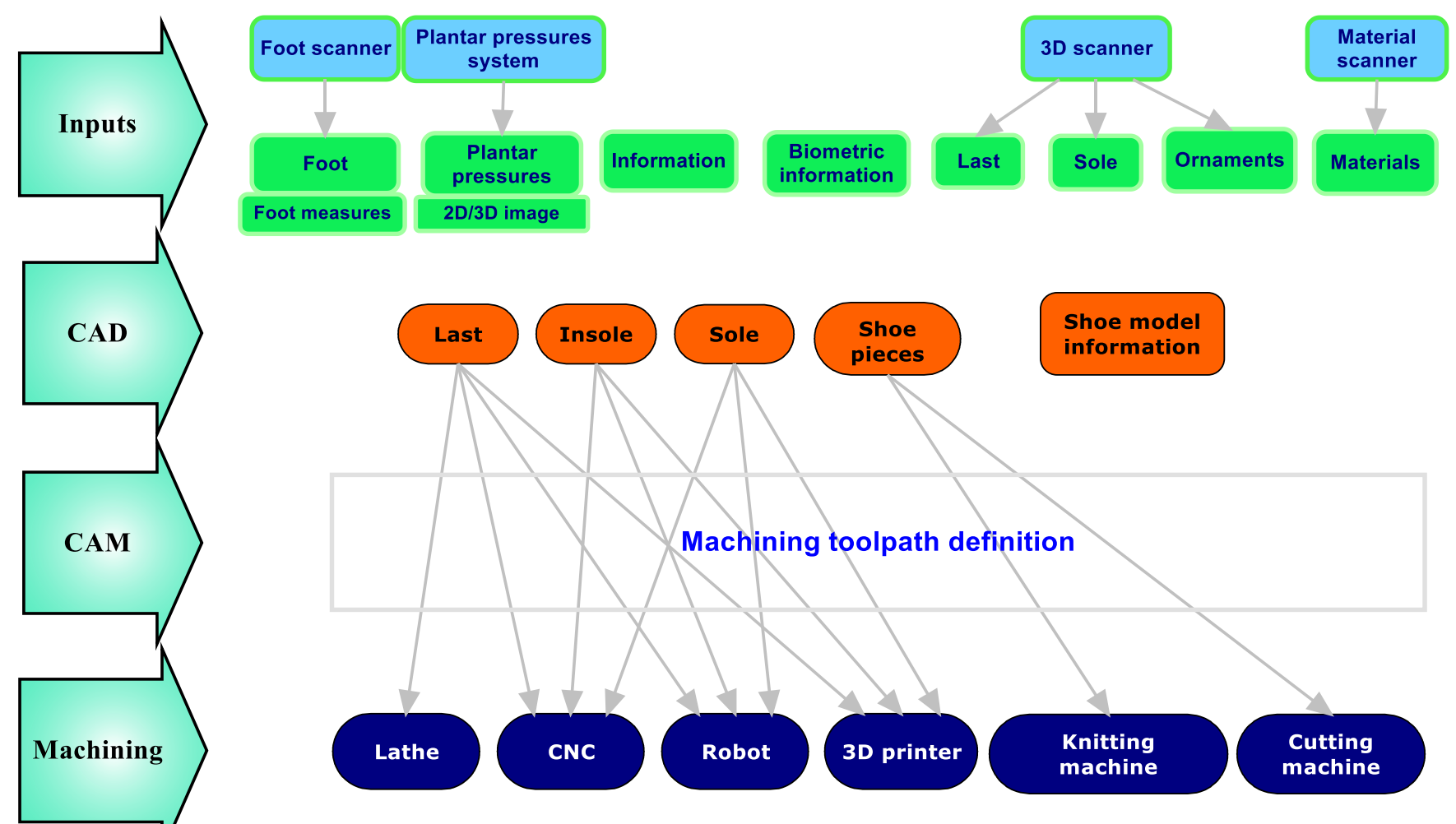

Fig 4: Footwear manufacturing process

The footwear manufacturing process (see Fig 4) starts taking the shoe last as a basis, and the model will be designed (or an existing one will be adjusted). As a result, the different pieces, linings, midsole, counter, etc., will be available. These components will vary according to the type of footwear to be manufactured (sports shoe, casual shoe, formal shoe, etc.).

Next, the last already dressed is needed (incorporating pieces, sole, etc.) to be able to design the sole or, in general, the component with which the shoe is going to rest on the ground. It may be a complete sole, a heel, a wedge, a platform or even, in some cases, a combination of several of these elements.

The different components that make up a shoe can be represented or designed using CAD tools. These tools will define the elements in different ways, and these will allow different operations to be carried out with them. It is important to take into account that shoes will have different sizes and a right/left shoe model is needed so as to design every component.

What kind of geometry does each element represent?

- Digitized foot. When a foot is digitized (see Fig 5), a point cloud is usually obtained, and from this point cloud a mesh is constructed.

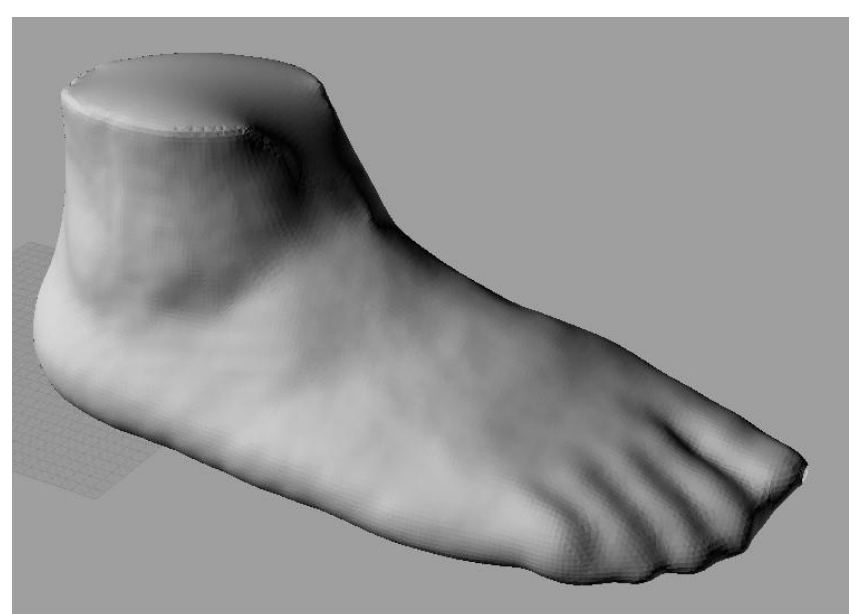

Fig 5: Rebuilt mesh from the digitization of a foot

- Shoe last. It is usually represented as a NURBS surface (see Fig 6).

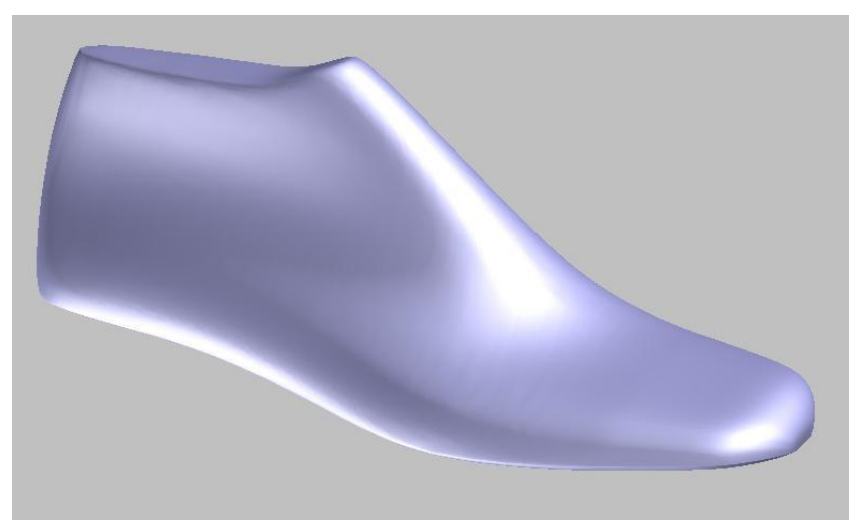

Fig 6: Surface of a last 
The last is one of the main components in the shoe manufacturing and it is mechanized in a turning lathe [23], [24].

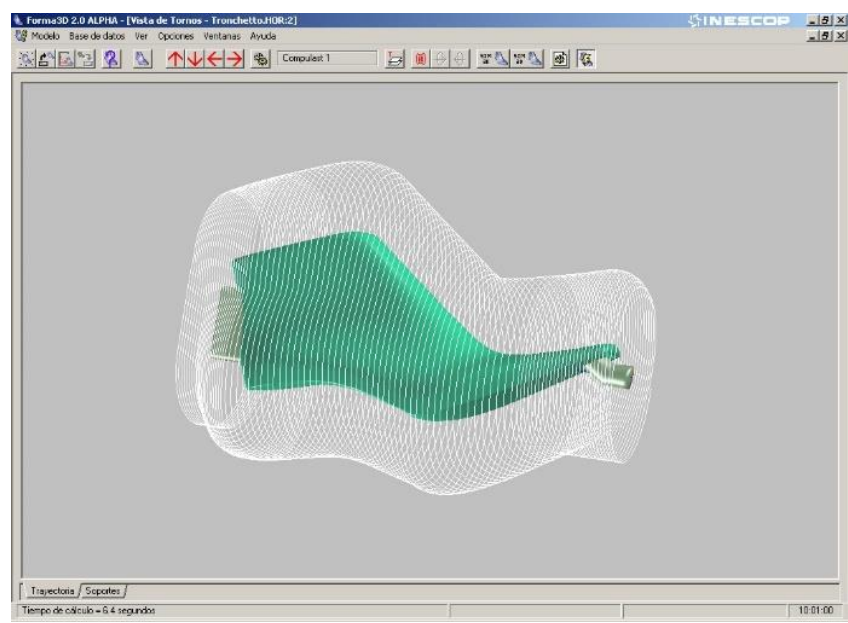

Fig 7:Finishing toolpath of a shoe last

The machining of the last starts with a pre-formed block, which has to be roughened with several toolpaths, and it ends with a finishing toolpath (see Fig 7). The result produces a plastic object (see Fig 8) that will be used as the "mould" for the shoe.

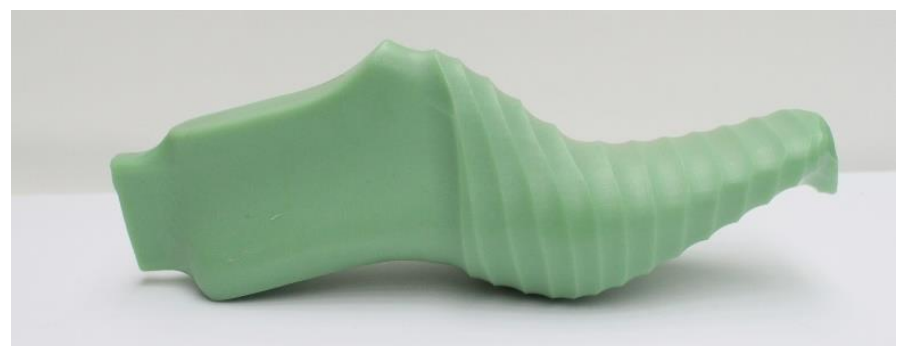

Fig 8: Mechanized last. Left part roughed and finished; right part roughed

Nowadays the use of 3D printed lasts (see Fig 9) to manufacture shoe prototypes is steadily increasing. This process allows to introduce modifications in a fast way. Depending on the parameters used to print the last, it could be used perfectly to produce a small set of shoes [25]. The thickness of the external wall and the internal structure, as well as the material, must be defined in an appropriate way and the elements necessary for the manufacture of shoes (tubes, joints, ...) must be incorporated into the design. During the shoe manufacturing process, the last will be subjected to different pressure and thermal stress processes (cold and hot).

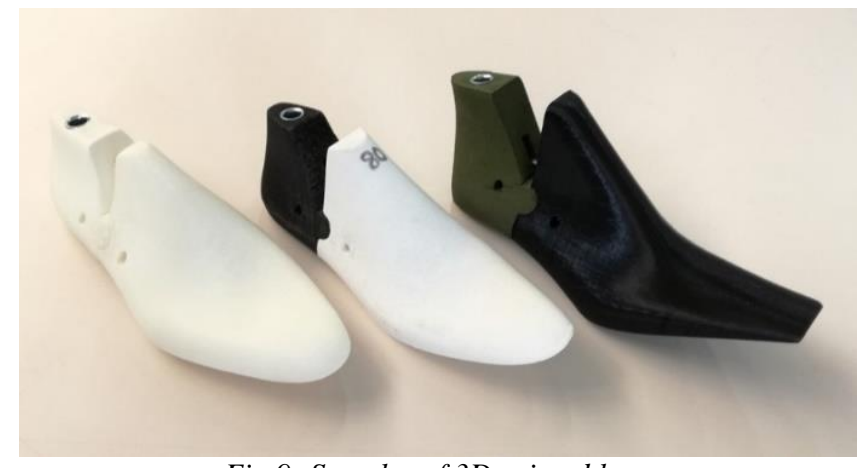

Fig 9: Samples of 3D printed lasts
- Insoles. It is represented as a polysurface or a mesh.

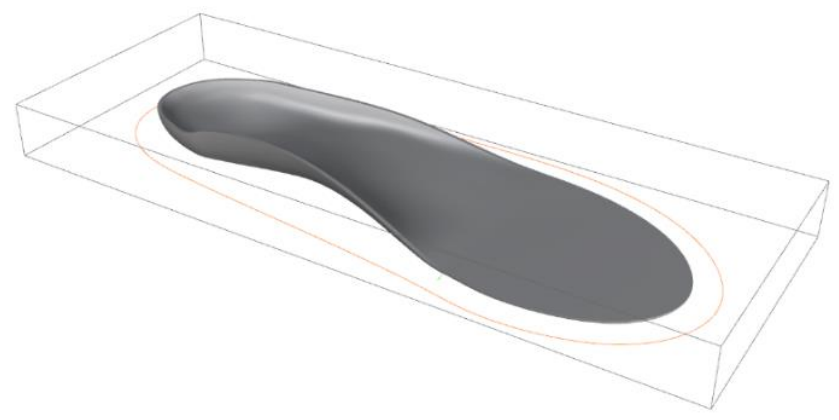

Fig 10: Insole

The insole (see Fig 10) could be customized or not. Most of the shoes use a standard 2D insole, but it is increasing the use of 3D insoles to improve comfort. This kind of insoles can be mechanized in CNC milling centres, producing directly the customized insole or the mould for mass production of insoles.
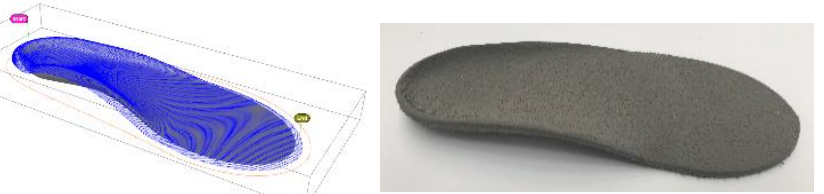

Fig 11: Left: insole's milling toolpath; Right: milled insole

Typical toolpaths to mechanize the insole in a milling machine are common roughing and finishing strategies (see Fig 11), without special options. It is also available the option to produce insoles using 3D printers (see Fig 12) [26].

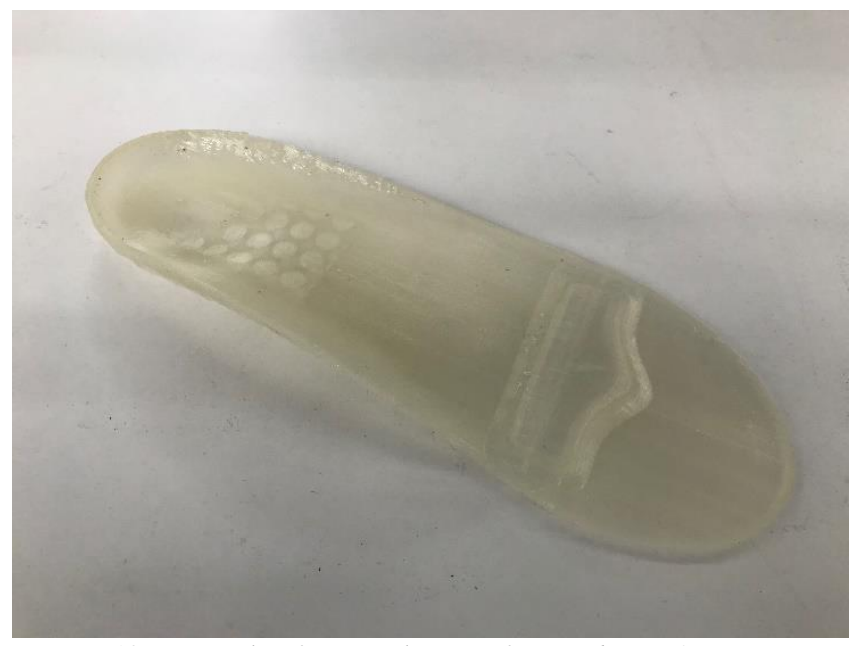

Fig 12: Example of an insole manufactured on a 3D printer

- Upper pieces. These parts are 2D curves (polylines, NURBS, B-Spline). Moreover, if the pieces have been designed from the 3D last and its flattening, surely the pieces will be in 3D, represented by polysurfaces (see Fig 13). 


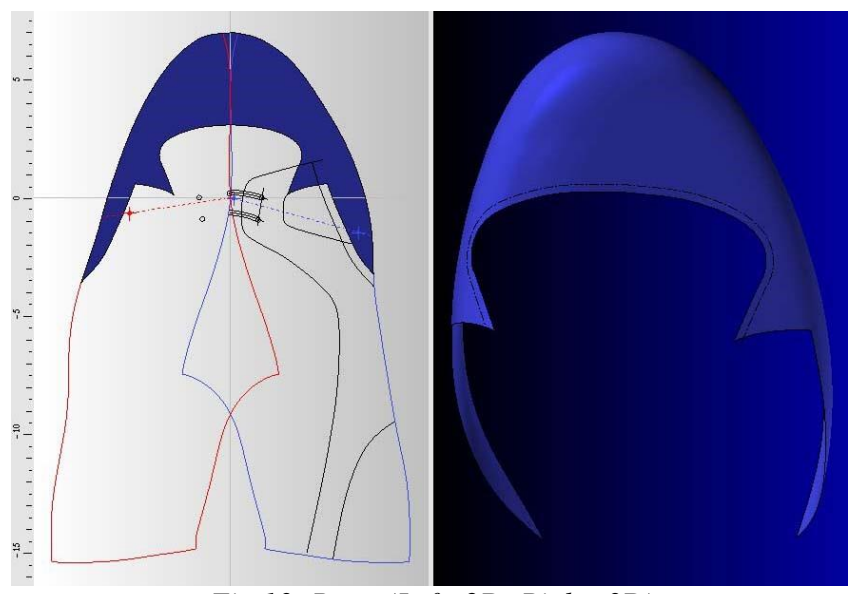

Fig 13: Parts (Left: 2D; Right: 3D)

These are produced by cutting leather or different synthetic materials on an automatic cutting table (see Fig 14). These kind of machines need a $2 \mathrm{D}$ toolpath and the pieces must be positioned properly in order to optimize the use of material.

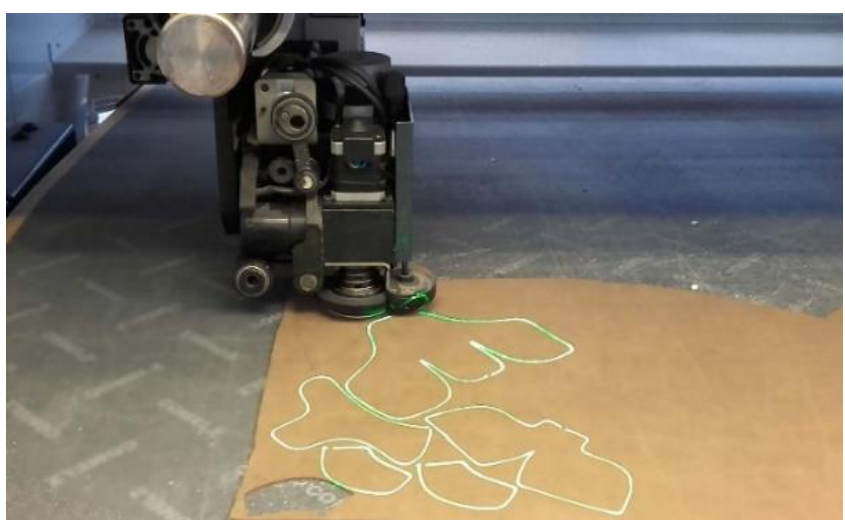

Fig 14: Automatic cutting machine projecting pieces

- Outsole / Heel / Wedge / Platform. They are usually represented as polysurfaces, although in some cases they are represented as meshes (see Fig 15).
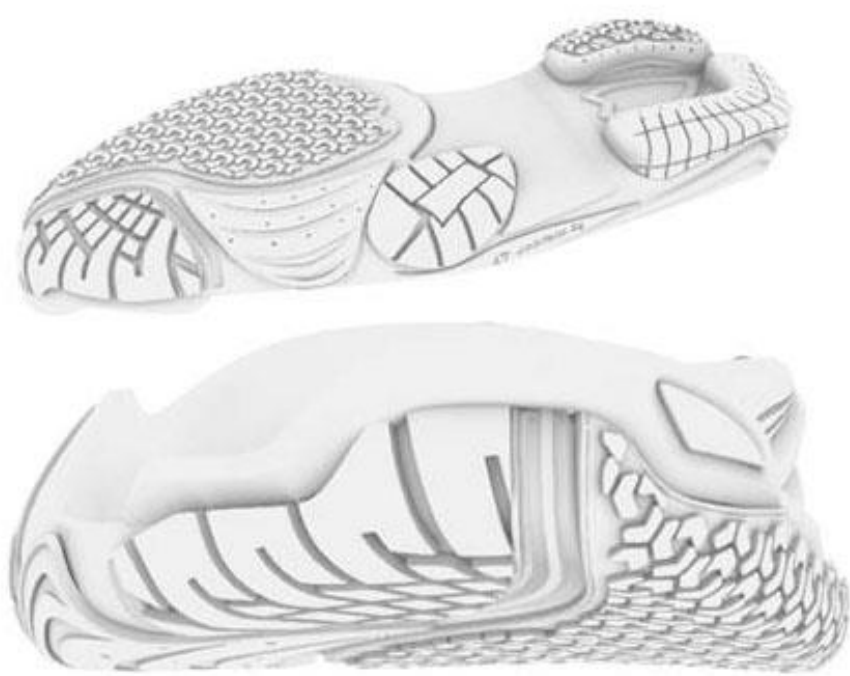

Fig 15: Footwear outsole designed with INESCOP Icad3DP

These components are not usually mechanized directly, unless the objective is the manufacture of a prototype, or in the case of heels, an aluminium male is machined (see Fig 16), and with that male, a mould will be created by a casting process.

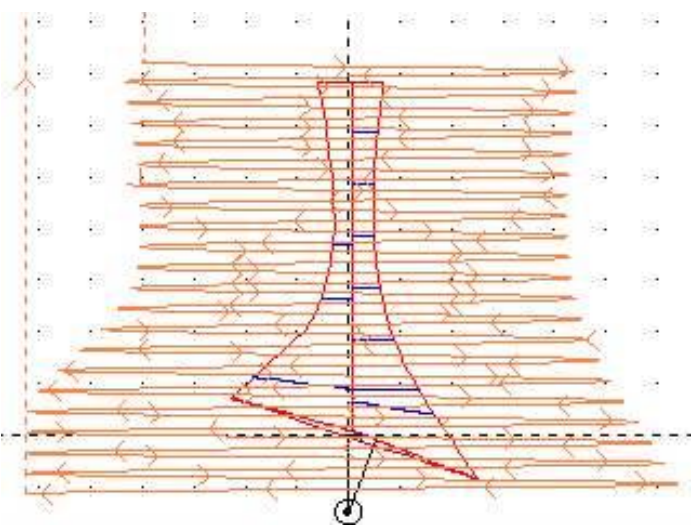

Fig 16: Milling toolpath of a heel

For the production of soles, designing a mould and mechanizing it in a CNC milling machine is mandatory.
Classical milling strategies are needed to mechanize the moulds.

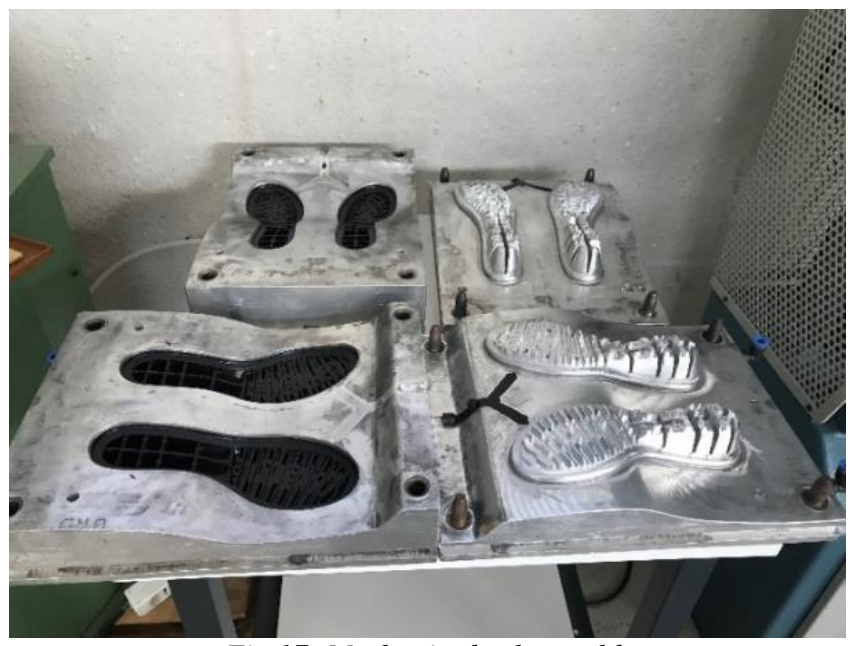

Fig 17: Mechanized sole moulds

The machining of an outsole mould (see Fig 17) is one of the more complex and expensive tasks: many paths and 
tolls are required, so it is very common to make prototypes using 3D printers (see Fig 18) to reduce costs.

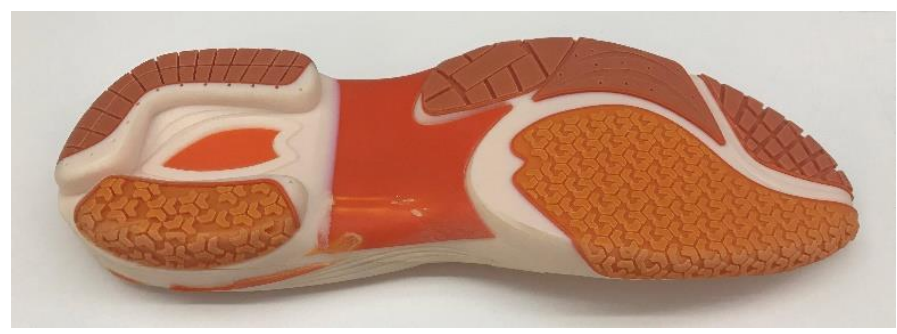

Fig 18: Footwear sole printed in $3 D$

The elements described are the main ones used in footwear manufacturing, but there are more components and machines, whose number varies according to the shoe model. Most of these elements can be represented and manufactured in the same way that the components showed above.

For the complete shoe, it is necessary to use additive manufacturing technology for producing fast prototypes (see Fig 19) to help manufactures decide some details before the production phase. All the elements are needed to print a $3 \mathrm{D}$ prototype with all kind of details.

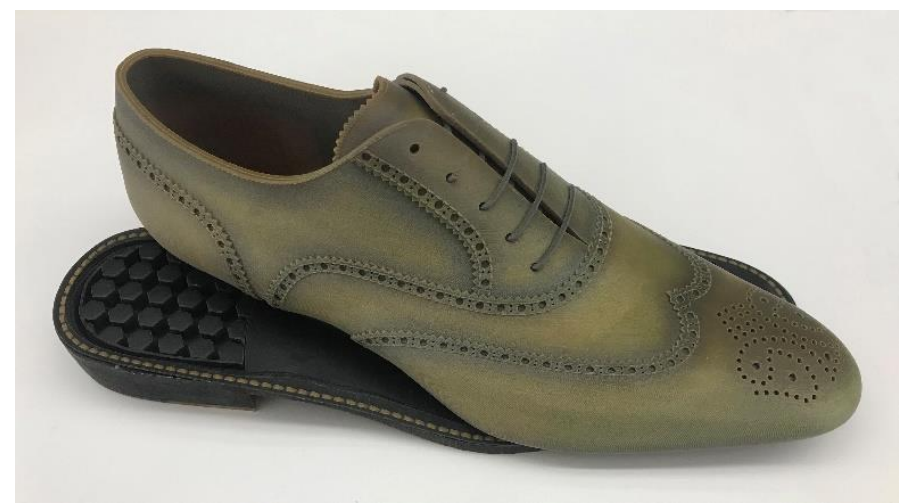

Fig 19: Shoe prototype produced in a $3 D$ printer

All the elements that make up the shoe are related, and the introduction of a modification in one of them leads to the modification of the rest of them (mainly if the modification affects the shoe last). Modifying any element involves changing the toolpaths to machine it. It is necessary to recalculate the paths, generate the files, and send them to the corresponding machine. Sometimes, the designer draws a component impossible to mechanize, and during the machining phase it is necessary to modify the geometries. The footwear industry uses many manual machines because of the complexity of generating toolpaths automatically. This is due to the high frequency of changes in models and their geometries, which makes it difficult to establish a relationship between the CAD phase and the manufacturing phase. Therefore, the introduction of STEP-NC could improve the footwear manufacturing process in this concern.

\section{Approach to integrate STEP-NC in the footwear industry}

From the software point of view, STEP-NC can contain the geometries mentioned above, but the greater complexity would remain in the machinery. Due to the diversity of machines used in different machinery manufactures, in which everyone has their different way of operating and format, most of them use proprietary formats, as shown in Table 1 . It is very unlikely that machinery manufacturers adopt STEP-NC in a first step.

There are 3 different ways to implement STEP-NC in a machine (see Fig 20), widely described in the bibliography [18], [27]-[29]:

- Conventional control. Incorporating STEP-NC to conventional controls through post-processing. In this case, existing controls can be used without modification. This type of control reads the STEP-NC code and generate files for legacy machines.

- New machine control. These controls have an integrated STEP-NC interpreter, so the programmed working steps are executed by the $\mathrm{CNC}$ kernel with the ability to generate trajectories.

- New intelligent control. This type of control is the most promising and is capable of performing machining tasks smartly and autonomously, based on the information contained in the STEP-NC file. Some examples of intelligent functions are: automatic feature recognition, automatic path generation (collision free) including control of approach and separation, automatic tool selection, automatic selection of cutting conditions, status monitoring, and status and result feedback.

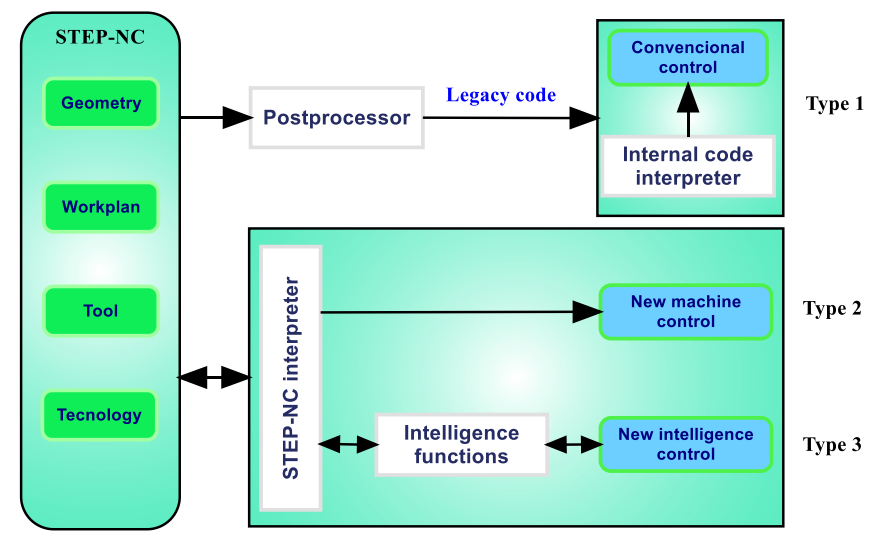

Fig 20: STEP-NC controls

The ideal situation is to implement a new intelligent control, although a progressive implementation would be the most suitable. Initially, a module could be developed to translate STEP-NC into native machine code, and then expand and incorporate features into it until smart control is achieved.

The first step to achieve this would be having CAD/CAM tools that would allow to integrate all the geometric components mentioned before, with their corresponding integrated machining orders according to the standard. Initially, these files would contain the toolpath information, so that only a translation from the STEP-NC format to the machine's native format would be necessary for machining the different parts. Thus, a type 1machine is achieved. 


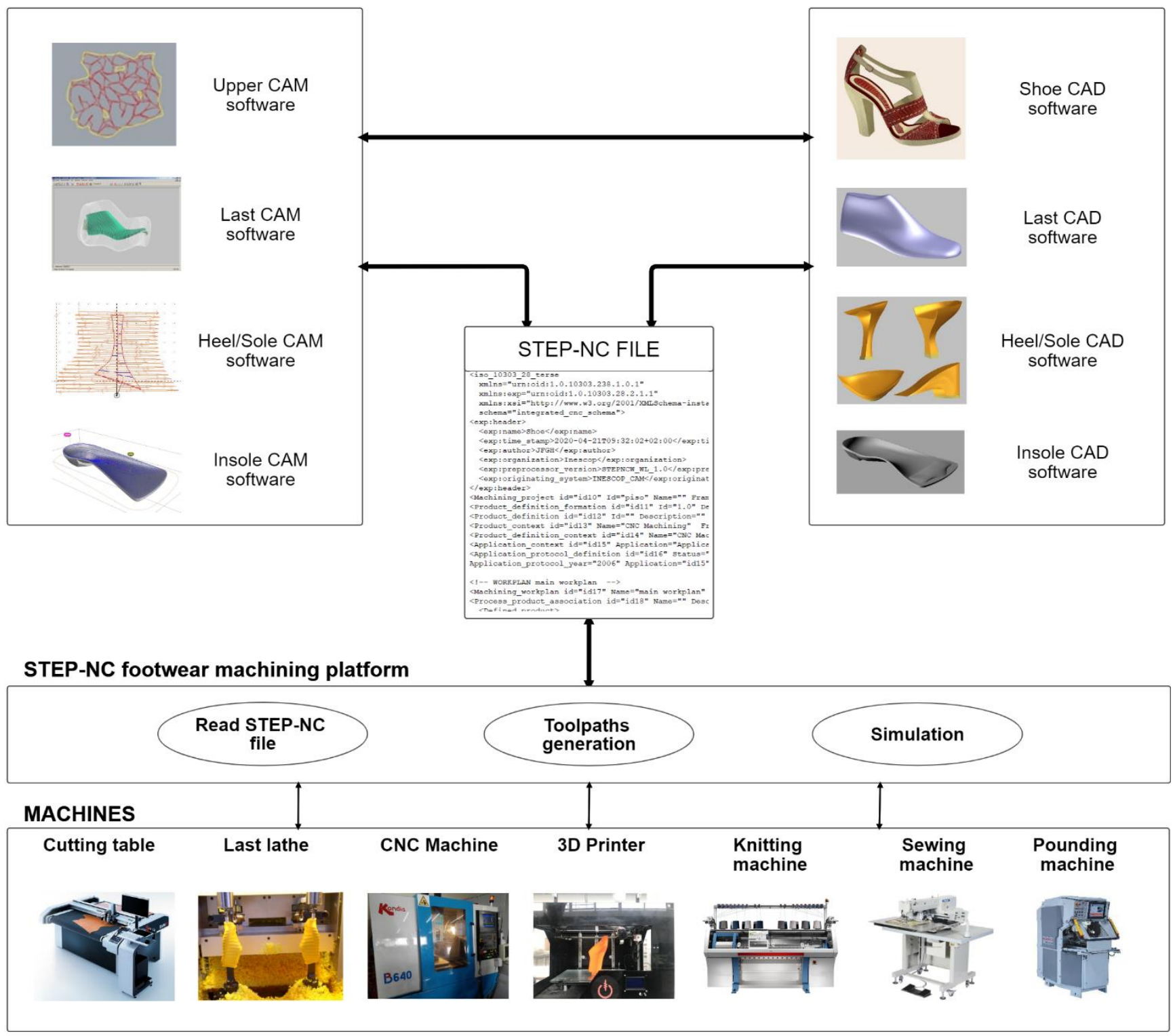

Fig 21: Relations of Step-NC file with software and machines

The next step would be to provide the machine with the required calculation capacity, thus removing this capacity from the CAM phase, which would only define the strategy and the appropriated parameters (strategy type, tool definition, steps...). This is the phase in which more computing power would be required in the machine and, for this reason, the initial approach would be to introduce systems for computing speed up through dedicated hardware, which would mean performing computing into devices such as FPGAs [23], [30], [31] or GPUs [32]. This could also be done through cloud computing [20].

The last step would be to have a smart system, which would be able to determine the best tool to perform each operation and adjust the trajectory according to the working conditions. An important aspect would be to detect if the machine has broken down during the machining process and change it at run time. To this end, it is important that the path calculation process is carried out quickly at the run time. It would be useless to have the path completely calculated and have the tool break at some point during the machining operation, because at that moment all the calculations would have to be recomputed, which could result in inactivity time in the machining process.
Once the different options that can be used for the implementation of STEP-NC have been defined, and given the variety and complexity of the machinery used, it is proposed to use a STEP-NC footwear machining platform. This platform (see Fig 21) acts as a bridge between STEP-NC files and the different machines.

This platform aims to:

- Focus on the footwear sector, taking into account their special needs: sizes, right/left foot, parameter optimization and simplification.

- Necessary flexibility in Industry 4.0 with the use of old machinery.

- Intelligent monitoring [33].

- Distributed/cloud manufacturing [11], [34], [35].

- Inspection and quality specification [36].

- $\quad$ Process planning (CAPP) [6], [37], [38].

- Closed loop machining to improve the data feedback [7], [27], [39], [40]. 
Not every one of these characteristics can be implemented in a type 1 implementation (see Fig 20), but they are a motivation for the implementation of this technology in new machines.

\section{Experimental test}

In order to test the feasibility of the proposed platform, two tests have been carried out: (1) machining a last in a lathe and (2) machining a heel in a milling machine; both elements should be manufactured in well-differentiated machines since they are relevant in the footwear industry.

\section{- Last manufacturing}

To mechanize a last, a module has been added to Inescop's software IcadFor to be able to generate data in Step-NC format. Using the CAM interface of the software, a file containing the machining work plan can be generated. To do this, the STEP-NC Write library from Step tools inc. [41] has been used. This library simply allows the export of Step-NC files in $\mathrm{CC} 1$ format. However, for these tests it has not been possible to include the geometry in the same file. To generate the different working steps, it is necessary to add the back and front support to the geometry of the last, in order to be able to machine it properly on a lathe, and to define the different steps according to the zone. In this example, 180 points per section have been used, with a main step of $1 \mathrm{~mm}$ and $0.5 \mathrm{~mm}$ in the heel and toe area $(20 \mathrm{~mm})$ to obtain better resolution in these areas (see Fig 22).

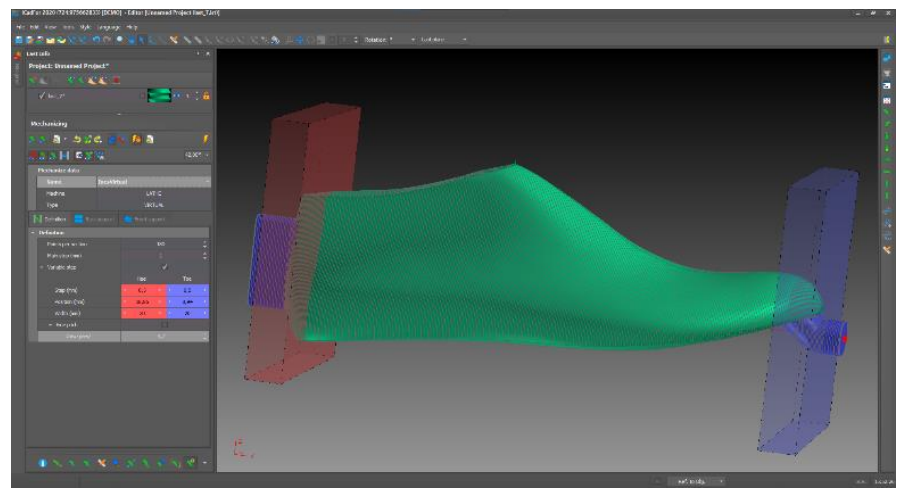

Fig 22: CAM parameters

Work plan and working steps definition. The file contains only one work plan with different working steps:

\section{○ Pre-roughing \\ $\circ$ Roughing \\ ○ Finishing}

An application has been developed to import the Step-NC file. Using a simple definition of tools and parameters, the application calculates the adequate toolpath for the machine, and generates the file for classical last lathes (.dg1 and .mod) (see Fig 23).

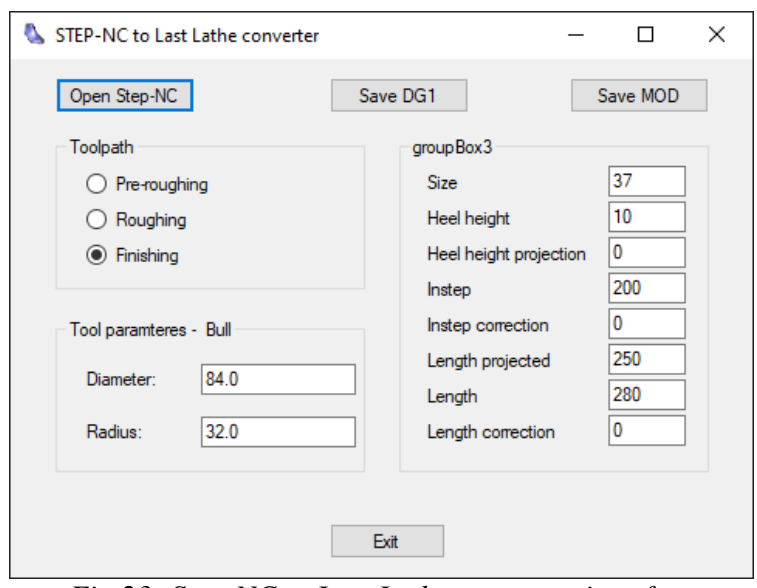

Fig 23: Step-NC to Last Lathe converter interface

- Heel manufacturing

To mechanize a heel made of aluminium (see result in Fig 27) and to create afterwards a mould with a casting process, we have used IcadCAM, a software developed by Inescop to generate milling toolpaths. This software includes some pre-created toolpaths to allow heel makers to create a heel in an easy way without using complex mechanizing parameters, as heels usually have a similar geometry. The best way to mill a heel is using a roughing strategy (see Fig 24 left) to adjust the heel height, and afterwards, most of the heels can be made using a spiral with a small step (see Fig 24 right). Toolpath parameters depend on the used tool; one of the most used tools is a bull with a $75 \mathrm{~mm}$ big radius and a $4 \mathrm{~mm}$-cut radius.
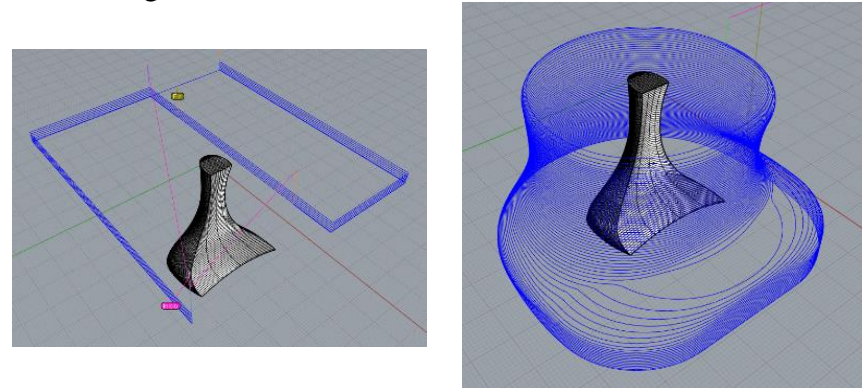

Fig 24: Machining toolpaths for a heel. Roughing (left) and finishing (right)

In this example we have used a $1 \mathrm{~mm}$-step for the roughing toolpath and a $0.3 \mathrm{~mm}$-step for the finishing toolpath.

This software has the property of generating nc files for many different milling machines, therefore, for testing the STEP-NC, we have added a new kind of machine to generate STEP-NC files. As in the example provided for the last, we have used the same STEP-NC Write library.

Work plan and working steps definition. The file contains a work plan with two working steps: one for roughing and the other for finishing.

With the same philosophy from the previous example, a simple application has been created to convert STEP-NC files to NC files in G-code format. No calculation module has been integrated in this test application. The STEP-NC file contains the toolpath points and the application simply reads the points and 
converts them to G-code format in order to send them to the machine. This application can postprocess the code to many different machines (see Fig 25), however, a Kondia B640 has been used together with Heidenhain 430 control.

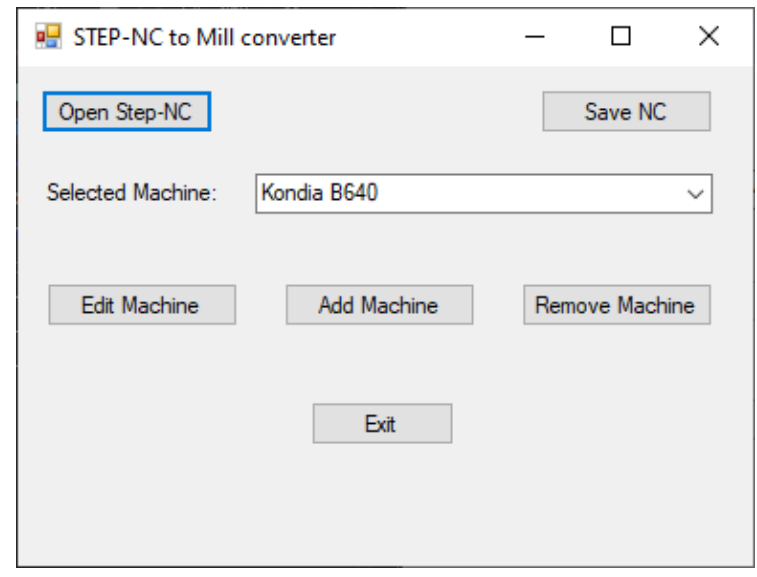

Fig 25: Step-NC to Mill converter interface

Some other controls have been integrated in this application. In the machine configuration view, the user can select the appropriate control and other parameters to generate the file correctly (see Fig 26).

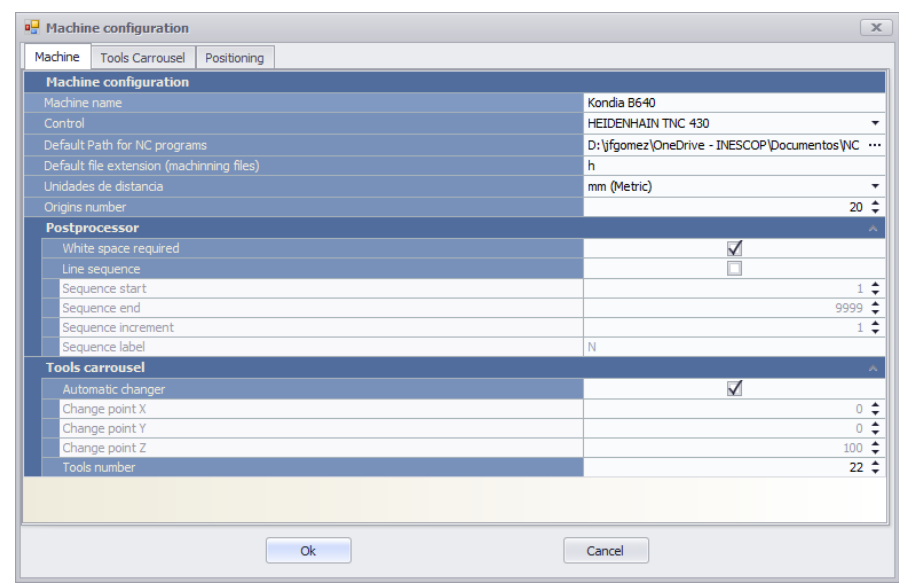

Fig 26: Machine configuration options

STEP-NC files have a complicated structure difficult to understand just at simple sight, without using an algorithm. Thus, we decided not to include any fragment of the file in this paper.

The main advantages of using Step-NC files in this case is the opportunity of generating files for different machines in a simple way, using the Step-NC as the source.

Step-NC AP238 has been designed for the integration of $\mathrm{CAD}, \mathrm{CAM}$ and manufacturing. This means that implementing all the functionalities is quite complex for the approach of this paper.

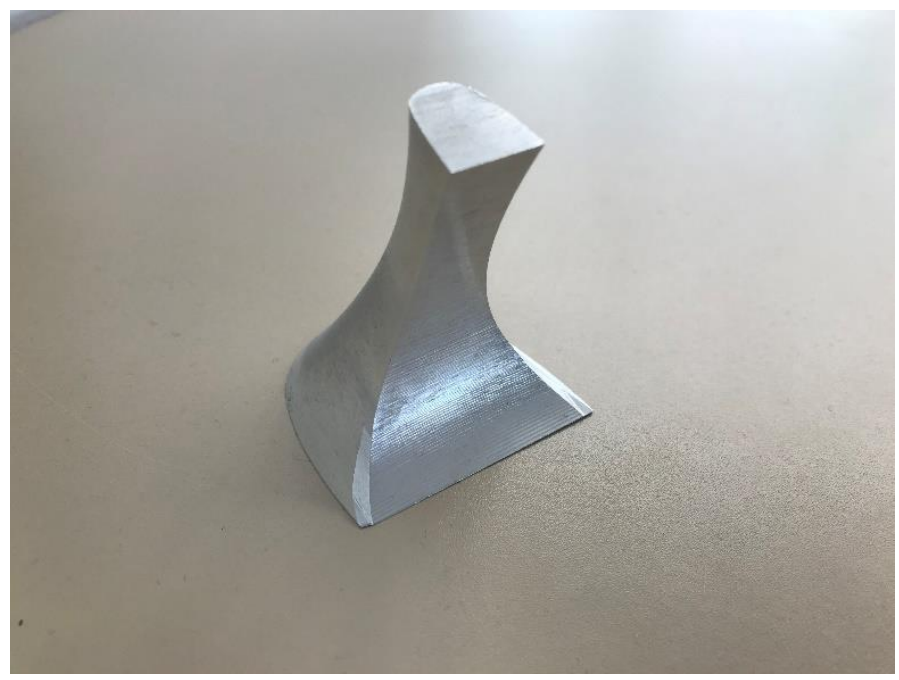

Fig 27: The heel milled in aluminium using a Kondia B640

\section{Conclusions}

In this paper, a platform has been proposed as a solution to adopt STEP-NC in the footwear industry for improvement of the shoe manufacturing process. Nowadays, new paradigms in industry, such as Industry 4.0 or smart factories, must also have an impact on traditional sectors, such as footwear, where most companies are SMEs and cannot afford large investments in technology.

The need for flexible production lines to adapt manufacturing to short production series and rapid changes in fashion make it difficult to apply new technologies.

This approach allows the use of legacy machinery, and additionally, improves the software layer interconnecting different $\mathrm{CAD}$ and CAM software applications with the machining level. Therefore, it can be used as a starting point to introduce changes in footwear machinery.

For future research, it is proposed to study in more detail the numerical controls of the described machinery, with the aim of developing intelligent controls that allow such machinery to generate complex toolpaths by itself, as well as to recover information from the sensors, thus trying to close the footwear manufacturing loop with the STEP-NC standard.

\section{References}

[1] P. Mueller and Y. T. Hyun, 'STEP-Compliant Data Interface for Numerical Controls (STEP-NC). STEP-NC Final Report'. Espirit Project EP 29708, Nov. 2001, [Online]. Available: http://www.step-nc.org/data/eu1_final_report.pdf.

[2] STEP-NC, 'STEP-NC official web page', Jan. 12, 2007. www.step-nc.org.

[3] ISO 10303-238, 'ISO10303-238 Industrial automation systems and integration - product data representation and exchange part 238: application protocol: application interpreted model for computerized numerical controllers.' 2007.

[4] ISO/TC 184/SC 4 Industrial data, 'ISO/DIS 10303-238 (second edition), Industrial automation systems and integration Product data representation and exchange - Part 238: Application protocol: Model based integrated manufacturing'. ISO, 2019, [Online]. Available:

https://www.iso.org/cms/render/live/en/sites/isoorg/contents/da ta/standard/07/20/72030.html.

[5] ISO14649-11, 'ISO14649-11 Industrial automation systems and integration - physical device control - data model for 
computerized numerical controllers - part 11: process data for milling.' 2004.

[6] J. Pobozniak and S. Sobieski, 'Extension of STEP-NC Data Structure to Represent Manufacturing Process Structure in CAPP System', Procedia Manuf., vol. 11, pp. 1692-1699, Jan. 2017, doi: 10.1016/j.promfg.2017.07.294.

[7] C. I. Riaño and A. J. Álvares, 'Feedback strategy for closedloop inspection based on STEP-NC', J. Phys. Conf. Ser., vol. 1065 , no. 8, p. 082014, Aug. 2018, doi: 10.1088/1742$6596 / 1065 / 8 / 082014$

[8] ISO 6983, 'ISO 6983-1:2009 Numerical control of machinesprogram format and definition of address words - Part1: data format for positioning, line motion and contouring control systems', ISO, 2009.

https://www.iso.org/cms/render/live/en/sites/isoorg/contents/da ta/standard/03/46/34608.html.

[9] EIA, 'EIA494B: 32 Bit Binary CL (BCL) and 7 Bit ASCII CL (ACL) Exchange Input Format for Numerically Controlled Machines - SAE International', 1992. https://www.sae.org/standards/content/eia494b/.

[10] T. Kramer, 'Evaluating manufacturing machine control language standards: An implementer's view', Proc. 2007 Workshop Perform. Metr. Intell. Syst., pp. 267-274, Jan. 2007, doi: 10.1145/1660877.1660916.

[11] X. W. Xu, Lihui Wang, and Yiming Rong, 'STEP-NC and function blocks for interoperable manufacturing', IEEE Trans. Autom. Sci. Eng., vol. 3, no. 3, pp. 297-308, Jul. 2006, doi: 10.1109/TASE.2005.862147.

[12] Heidenhain, 'Heidenhain Conversational Programming'. Jul. 1999, [Online]. Available: https://content.heidenhain.de/doku/tnc_guide/pdf_files/TNC40 0/280472-xx/bhb/322_938-24.pdf.

[13] CEN/ISSS, 'CWA 15043 Proposal for a XML-based format for storage and exchange of design data in the footwear industry'. Jul. 2004.

[14] M. Rauch, R. Laguionie, J.-Y. Hascoët, and X. Xu, 'Enhancing CNC Manufacturing Interoperability with STEP-NC', 2010.

[15] E. Rodriguez and A. Alvares, 'A STEP-NC implementation approach for additive manufacturing', Procedia Manuf., vol. 38, pp. 9-16, Jan. 2019, doi: 10.1016/j.promfg.2020.01.002.

[16] S. Zivanovic, N. Slavkovic, and D. Milutinovic, 'An approach for applying STEP-NC in robot machining', Robot. Comput.Integr. Manuf., vol. 49, pp. 361-373, Feb. 2018, doi: 10.1016/j.rcim.2017.08.009.

[17] B. Solvang, L. K. Refsahl, and G. Sziebig, 'STEP-NC Based Industrial Robot CAM System', IFAC Proc. Vol., vol. 42, no. 16, pp. 245-250, Jan. 2009, doi: 10.3182/20090909-4-JP2010.00043

[18] W. Xiao, L. Zheng, J. Huan, and P. Lei, ‘A complete CAD/CAM/CNC solution for STEP-compliant manufacturing', Robot. Comput.-Integr. Manuf., vol. 31, pp. 1-10, Feb. 2015, doi: 10.1016/j.rcim.2014.06.003.

[19] J. Garrido Campos and R. Marín Martín, 'Modelling and implementing circular sawblade stone cutting processes in STEP-NC', Robot. Comput.-Integr. Manuf., vol. 26, no. 6, pp. 602-609, Dec. 2010, doi: 10.1016/j.rcim.2010.06.027.

[20] G. M. Martinov, A. B. Ljubimov, and L. I. Martinova, 'From classic CNC systems to cloud-based technology and back', Robot. Comput.-Integr. Manuf., vol. 63, p. 101927, Jun. 2020, doi: 10.1016/j.rcim.2019.101927.

[21] M. Mourad, A. Nassehi, and D. Schaefer, 'Interoperability as a Key Enabler for Manufacturing in the Cloud', Procedia CIRP, vol. 52, pp. 30-34, Jan. 2016, doi: 10.1016/j.procir.2016.07.051.

[22] M. Davia-Aracil, 'Modelado geométrico biodeformable del pie. Aplicación a la fabricación de calzado personalizado', Universidad de Alicante-Inescop, Inescop, 2011.

[23] A. Jimeno, J. L. Sánchez, H. Mora, J. Mora, and J. M. GarcíaChamizo, 'FPGA-based tool path computation: An application for shoe last machining on CNC lathes', Comput. Ind., vol. 57, no. 2, pp. 103-111, Feb. 2006, doi:

10.1016/j.compind.2005.05.004.
[24] S. Cuenca-Asensi, A. Martínez-Álvarez, A. Jimeno-Morenilla, and J.-L. Sanchez-Romero, A hardware/software architecture for tool path computation: an application to turning lathe machining. IEEE, 2007.

[25] INESCOP, 'ADAPT3D - Metodologías de impresión 3D adaptativas para el desarrollo de hormas y fabricación de prototipos de calzado', Deliverable, 2018. [Online]. Available: https://www.inescop.es/es/inescop/actividad/proyectos-i-di/proyectos-i-d-i-ivace/ivace/18-2018/209-adapt3d.

[26] M. Davia-Aracil, J. J. Hinojo-Pérez, A. Jimeno-Morenilla, and H. Mora-Mora, '3D printing of functional anatomical insoles', Comput. Ind., vol. 95, pp. 38-53, Feb. 2018, doi: 10.1016/j.compind.2017.12.001.

[27] P. Hu, Z. Han, H. Fu, and D. Han, 'Architecture and implementation of closed-loop machining system based on open STEP-NC controller', Int. J. Adv. Manuf. Technol., vol. 83, no. 5, pp. 1361-1375, Mar. 2016, doi: 10.1007/s00170015-7631-z.

[28] M. Rauch, R. Laguionie, J.-Y. Hascoet, and S.-H. Suh, 'An advanced STEP-NC controller for intelligent machining processes', Robot. Comput.-Integr. Manuf., vol. 28, no. 3, pp. 375-384, Jun. 2012, doi: 10.1016/j.rcim.2011.11.001.

[29] S. H. Suh, B. E. Lee, D. H. Chung, and S. U. Cheon, 'Architecture and implementation of a shop-floor programming system for STEP-compliant CNC', Comput.-Aided Des., vol. 35, no. 12, pp. 1069-1083, Oct. 2003, doi: 10.1016/S00104485(02)00179-3.

[30] A. Jimeno-Morenilla, A. Martinez, S. Cuenca, and J. L. Sanchez-Romero, 'Accelerating tool path computing in CAD/CAM: A FPGA architecture for turning lathe machining', in 2007 International Conference on Field Programmable Logic and Applications, Aug. 2007, pp. 702705, doi: 10.1109/FPL.2007.4380749.

[31] S. Cuenca, A. Jimeno-Morenilla, A. Martínez, and R. Maestre, 'Hardware approach to tool path computation for STEP-NC enabled CNC: A case study of turning operations', Comput. Ind., vol. 62, no. 5, pp. 509-518, Jun. 2011, doi: 10.1016/j.compind.2011.02.001.

[32] V. Morell-Giménez, A. Jimeno-Morenilla, and J. GarcíaRodríguez, 'Efficient tool path computation using multi-core GPUs', Comput. Ind., vol. 64, no. 1, pp. 50-56, Jan. 2013, doi: 10.1016/j.compind.2012.09.009.

[33] W. Liu, C. Kong, Q. Niu, J. Jiang, and X. Zhou, 'A method of $\mathrm{NC}$ machine tools intelligent monitoring system in smart factories', Robot. Comput.-Integr. Manuf., vol. 61, p. 101842, Jul. 2019, doi: 10.1016/j.rcim.2019.101842.

[34] M. H. Mourad, A. Nassehi, D. Schaefer, and S. T. Newman, 'Assessment of interoperability in cloud manufacturing', Robot. Comput.-Integr. Manuf., vol. 61, p. 101832, Feb. 2020, doi: 10.1016/j.rcim.2019.101832.

[35] A. Nassehi, S. T. Newman, and R. D. Allen, 'The application of multi-agent systems for STEP-NC computer aided process planning of prismatic components', Int. J. Mach. Tools Manuf., vol. 46, no. 5, pp. 559-574, Apr. 2006, doi: 10.1016/j.ijmachtools.2005.06.005.

[36] C. Riaño, E. Rodriguez, and A. J. Alvares, ‘A Closed-Loop Inspection Architecture for Additive Manufacturing Based on STEP Standard', IFAC-Pap., vol. 52, no. 13, pp. 2782-2787, Jan. 2019, doi: 10.1016/j.ifacol.2019.11.629.

[37] Y. Yusofland and K. Case, 'STEP Compliant CAD/CAPP/CAM System for Turning Operations', presented at the Congress on Engineering and Computer Science, Oct. 2008.

[38] X. W. Xu and Q. He, 'Striving for a total integration of CAD, CAPP, CAM and CNC', Robot. Comput.-Integr. Manuf., vol. 20, no. 2, pp. 101-109, Apr. 2004, doi: 10.1016/j.rcim.2003.08.003.

[39] C. Danjou, J. Le Duigou, and B. Eynard, 'Closed-loop Manufacturing, a STEP-NC Process for Data Feedback: A Case Study', Procedia CIRP, vol. 41, pp. 852-857, Jan. 2016, doi: 10.1016/j.procir.2015.12.034. 
[40] F. Zhao, X. Xu, and S. Xie, 'STEP-NC enabled on-line inspection in support of closed-loop machining', Robot. Comput.-Integr. Manuf., vol. 24, no. 2, pp. 200-216, Apr. 2008, doi: 10.1016/j.rcim.2006.10.004.

[41] D. Lofredo, 'Step application protocols overview of Tools'. Steptools inc., 2007. 


\section{An approach to implement STEP-NC in the footwear industry}

\section{A R T I C L E I N F O}

\section{Keywords:}

Step-NC

Footwear

Machining

$\mathrm{CNC}$

$\mathrm{CAD} / \mathrm{CAM}$

Smart factories

Industry 4.0

\begin{abstract}
A B S T R A C T
There is a growing need to automate the footwear industry by introducing new methods and tools to improve footwear production. The use of CAD tools for the design of shoes and their components is increasingly common, but it is a sector in permanent adaptation to socio-economic changes where it is therefore complicated to incorporate high-tech machinery. The introduction of improvements in production is a necessity, so the use of technologies that allow the adaptation of old machinery with the latest technologies in the area of CAD/CAM would be an important advantage for the sector.

So far, each component is designed and manufactured separately. In this way, the real dependence that exists between the different components required for manufacturing footwear means that a change in any of these elements implies a redesign (CAD level) of the rest of the elements. This fact increases the manufacturing cost. It is also necessary to modify the way of manufacturing the product (CAM level), which is a complex manual process in many cases. The introduction of changes in an industrial environment with limited resources means a very slow implementation.

In this paper, a platform based on STEP-NC is defined to show the advantages that its implementation in footwear sector would imply, by relating all the elements involved in footwear manufacturing: CAD tools that generate the geometries of the components, CAM tools that define the paths for their machining, and the different machines that manufacture these components. Furthermore, additional advantages would be incorporated, such as process control, supervision, inspection, allowing information to flow in all directions.
\end{abstract}

\section{Introduction}

Traditionally, in the field of footwear manufacturing software, it has been usual to find different CAD/CAM applications that use different formats for storing and processing information. Most footwear applications have the possibility to export information in some standard format that allows interconnection with other applications. With regard to machines that produce most of the different parts that make up a shoe, the problem is similar, but in this case, there is usually no export or exchange module. The data has to reach the machine in a format that it can understand, and this code is usually different from the one used by a similar machine from another vendor.

To achieve this communication, applications often use different formats, usually plain text, representing different geometric objects; from files containing point clouds or polylines, to more complex and structured files such as those following the DXF, STL, IGES or STEP format. In the same way, there are also files containing machining information.

With the rise of the trend known as Industry 4.0, the interconnection of different systems and the needs to include, increasingly, complementary information in the integrated manufacturing process, there is a need to find a format that facilitates this process.

The STEP-NC [1], [2] standard is a powerful tool for the integrated management of the intercommunication of the different subsystems involved in the manufacturing process. This standard allows the exchange of information in a simple way. STEP-NC (ISO 10303 ap238 [3], [4] and ISO 14649 [5]) is based on the STEP standard (ISO 10303) as a geometrical basis, to which machining related extensions have been added. This format allows the incorporation of geometrical information, machining information and other types of information such as comments or indications. It also allows bidirectionality between design (CAD), machining (CAM) and manufacturing (CNC). With the appropriate extensions, this standard can also include process planning information (CAPP) [6], which means that it cannot only contain information about design or machining, but also about how the manufacturing process is to be done. It could also include information for inspection (closed-loop inspection) [7] thus controlling the whole manufacturing process.

The aim of this paper is to make a model for the use of the STEP-NC standard as a tool to interconnect all the sub-systems needed in the footwear industry, from the design of models to the manufacture of the shoes, on the basis that the interconnection between the design software and the $\mathrm{NC}$ machines is a requirement for smart factories and the communication must be bidirectional. Section 2 provides a background about standards in footwear industry. Section 3 explains the main features of STEP-NC. Section 4 shows the main features that STEP-NC should cope with in footwear manufacturing. Section 5 introduces an approach to integrate STEP-NC in the footwear industry. Section 6 shows an experimental test in the use of STEP-NC to mechanize a last and 
a heel, and finally, Section 7 summarizes the contributions of the research work.

\section{Research background}

The first machining systems began to appear in the 1960s. These systems had small programs to make different parts, but they were rigid and proprietary systems. Some of them even used punch cards to be programmed.

Later, the Electronic Industry Association began the development of a format that in 1980 would become the RS274D standard (ISO 6983), known as G-Codes [8]. It is based on preparatory $G$ functions (G0-G99), alternative $M$ (or machine) functions, axis movement commands (X, Y, Z, A, B, C), F (Feed rate) and S (Spindle Speed) commands, as well as T tool and $\mathrm{N}$ block identification commands. This system is widespread, but has some shortcomings:

- It focuses on programming the tool path with respect to the axes (instead of a machining task with respect to a part). It describes how the machining is to be done, not what to do. It is focused on the movement of the machine axis using a specific tool, but it does not define if the operation is performing a roughing or a finishing operation, neither indicates the milling strategy.

- The standard defines the syntax, but in many cases, it produces ambiguous semantics.

- Each manufacturer complements the standard according to their own needs, since the standard does not contemplate them (and this is why the files are usually not portable).

- A specific post-processor is needed for each machine.

- The flow of information is unidirectional (from design to manufacturing) and makes it impossible to feedback possible changes required from the manufacturing phase.

- At machine level, it is very difficult to control the path execution, and it is very complicated to change it.

- The data of the part to be machined are not available on the machine, which makes the verification and simulation tasks very difficult or even impossible.

G-Codes is deeply rooted, both in the way workers conceive the manufacturing process, and in the structure and architecture of the machines.

In 1992, the Electronics Industries Association introduced EIA-494 Basic Control Language (BCL), defined as a language that was portable and independent of the machine, but did not contain any model information [9], [10].

In 1999, Function Blocks (IEC-61499) for distributed industrial processes and control systems appeared. It is based on explicit events by the model and finite state automatons. Each function block encapsulates certain machining tasks (roughing a face, finishing a hole, drilling). One block function can encapsulate others to make more complex functions. Each machine implements its own way of performing each block function, adjusting to its characteristics. This means that the result can be different on two different machines. Basic block functions are defined, which are executed as an atomic unit [11]. A flow of events is also defined, which may be complex and supports a bidirectional information flow between the machining and design phases. This system has not been widely used.

In parallel, many machine manufacturers have developed their own language as an alternative to G-Codes. For example, Heidenhain uses both G-Codes and its own language called "Conversational Language"[12].

STEP-NC, on which the proposal of this paper is focused, starts in 1999 to complete the STEP format (which was initially designed to improve IGES, offering a neutral data exchange method), adding machining information to the geometry data provided by STEP. The machining information describes tasks at a high level with respect to geometry [1].

In 2004, through a European project, a standard called ShoeML was developed [13]. In this format many of the needs of the footwear manufacturing industry were expressed, especially in the definition of geometries. XML was used to store geometrical information, but in the machining stage it only concerned the cutting tables. This format is still used although by very few manufacturers, as most systems use proprietary formats.

\section{STEP-NC, the standard}

In 1999 a project called STEP-NC was started by the European group ESPRIT and was continued in 2001 as an international project, IMS STEP-NC, finally giving rise to ISO14649 where a model for CNC controls was defined; its aim was to replace ISO 6983. Later on, the CNC model was integrated into STEP (ISO10303) to produce ISO10303 ap238. It uses STEP to define the geometry and complements it with machining data. STEP-NC describes what to do at a high level, through tasks: pre-drilling, drilling, roughing, fine tuning, ... It presents the following advantages:

- $\quad$ Easily defined tasks.

- Self-documenting, contains CAD and CAM information.

- It eliminates the use of machine-specific post processors.

- It is safer and more adaptable as it is independent of the machine vendor.

- It provides a complete and structured data model, associated with geometry and technical information, therefore, no information is lost throughout the various stages of the process.

- Changes in the production stage can be stored, providing two-way feedback between design and manufacturing.

- Object-oriented vision.

- XML files can be used, allowing electronic exchange.

STEP-NC is being implemented in many sectors, which take the standard definition and customize or adjust it for their specific characteristics. Sectors such as the automotive or aeronautical industries are directly involved in the development of STEP-NC, taking direct advantage of the benefits that this technology is introducing. Similarly, STEP-NC has been developed to be used on machines such as machining centres and lathes. For its use on other types of machines, the standard follows a continuous process of updating. 
The current trend in the CAD field is to use the STEP format as an exchange format for geometry files; if CAM information is also required, it is strongly recommended to use STEP-NC. A few years ago it was very common to use the IGES format (Initial Graphics Exchange Specification) for the exchange of geometric information (there was no machining information), but since the birth of STEP in 1994, all interest in continuing to develop IGES was lost (the last version was published in 1996). Therefore, the initial idea of STEP-NC to replace IGES is being fulfilled. In addition, STEP-NC meets the needs of incorporating machining information.

As reference, STEP-NC can be used in CNC milling machines [14], 3D printers [15], machining robots [16], [17], CAMs [18], circular sawblades [19], ...

\section{STEP-NC in the footwear sector}

The footwear manufacturing sector has its own characteristics, among which it is worth mentioning that it is very traditional and conservative. When technology was first introduced in this sector, it had to provide a complete $\mathrm{CAD}+\mathrm{CAM}+\mathrm{Machine}$ solution. In this way, most systems were closed systems. For instance, with regard to last manufacturing, the manufacturers of lathes limit the input to their own format (although internally they usually use standard numerical controls slightly customized) and you just can use the lathe with their proprietary format, generated by themselves. In heel and sole manufacturing, machining centres or CNC milling machines are often used. In this case, most machines use GCodes for their operation, but each one has customized the standard according to its needs. The manufacture of patterns and pieces is carried out on computer-controlled cutting tables, where the format casuistry is very varied, from DXF formats (ASCII to represent the points) and simple instructions to raise/lower the head, to more complex languages, such as HPGL, developed by HP for the control of plotters. Other machines use their own format, as most of the machines have been modified to support shoe production, allowing support to produce right/left-handed parts (mirroring the component) and sorting to produce different shoe sizes.

The footwear sector is undergoing a change with the arrival of Industry 4.0 since, on the one hand, large footwear productions are being made in emerging countries and, on the other hand, firms specialized in quality footwear are betting on short production and customized footwear. This trend demands a strong control, both in the design and manufacturing phases, requiring a lot of investment in software $(\mathrm{CAD} / \mathrm{CAM})$ as well as in machinery. This investment is expensive, so the trend is to use machines capable of machining different components. For example, robots could be used to machine different parts of a shoe: lasts, heels, insoles, and even allow the manipulation of different components. In this process of change, the need for a manufacturing oriented language is emerging, so that it is not only independent of the type of machine for which it is intended, but also allows for the incorporation of additional information, two-way communication between design and machining, as well as geometric references that facilitate subsequent verification. At the same time, new machines and devices are bursting into this classic sector: 3D printers, digitizers, virtual reality devices, and so on.

Since the standard allows for the integration of geometry, machining and complementary information in the same document, a proposal will be made considering the specific needs of the footwear sector.

To make a complete shoe (see Fig 1), and following the complete process from scratch, the digitized foot of the person, or a standard model, would be needed. From this foot model, and especially if the foot has special or abnormal characteristics, a custom-made last would have to be designed, as well as an insole if any pathological condition of that foot has to be corrected. In addition, a sole would be needed for the shoe, as well as the different pieces and linings that will form the shoe. If it is necessary to manufacture customized footwear, it would only be required to add the data related to customization (digitized foot, measurements, etc.) from the preceding proposal. Otherwise, the information would be the same: last, insole, sole, upper parts and linings, information on the grading, sizes, etc.

With this data, all the geometric information needed to start the manufacturing process would be available. Based on these geometries, it would be necessary to decide how to manufacture them. In the CAM section, the way the different components are going to be machined would be determined.

The shoe last would be manufactured on a CNC lathe. A machining centre (CNC) would be used to manufacture the insole, the heel/sole, or its moulds. The uppers and the lining would be machined on a cutting table. During the shoe manufacturing process, many different machines are used, and many of them need information on the shoe geometry to make the appropriate toolpath.

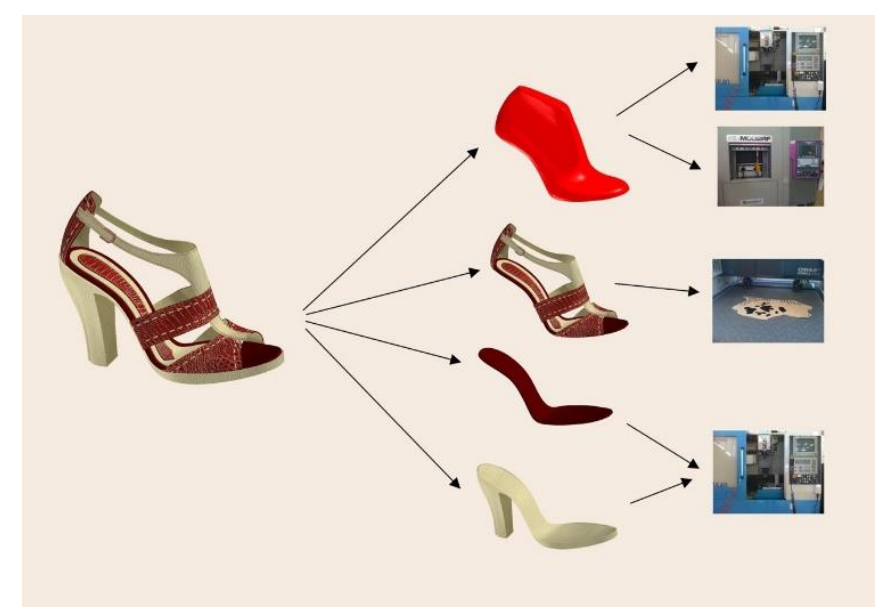

Fig 1: A shoe, its components and where it is manufactured

Once the strategies for machining each of the different geometries have been defined, the resulting file would be sent to the machine. It would generate the path following the instructions indicated in the CAM specifications. When operating the machine, the worker can access all the information and, if necessary, complement or modify it. For example, if the specific tool indicated in the CAM is not available, a similar tool could be used and produce the same result. The strategy parameters could also be modified dynamically; for example, if the operator observes, during machining, that the tool is suffering from a high stress level because the step is too large, he could adjust the parameter and set the step as required. If this could not be done, the machine would have to be stopped, the strategy parameters would have to be edited in the CAM, the machining file would have to be generated again, sent to the machine and started again. 
It is very common that during the manufacturing process of the complete shoe, or after the prototyping, the shoe last may change to solve a design problem or to make the shoe more comfortable. The complete shoe depends on the last, so all the different parts and components need to be updated.

On the other hand, the information that accompanies all the geometry may be very important. Let's imagine that, when including the information of the digitized foot, the person who scanned it could add comments indicating that a particular area of the foot has to be discharged. This information will be used by the designer of the insole, but it will also be available to the worker who has to manufacture it.

In STEP-NC, the path itself is optional (as opposed to Gcodes, where it is essential) and therefore the numerical controls need to be able to generate this path. In many cases, this means taking the machining calculation process from the CAM stage computer to the machine. Therefore, in order to use the STEPNC standard and take advantage of its benefits, all machines would have to be updated, since they would need a higher level of intelligence and autonomy.

Considering that the footwear sector is particularly sensitive to socio-economic and regulatory changes, which very often occur in relatively short periods of time, updating machinery to take advantage of the novelties provided by these new technological solutions is a very important investment over the years.

It is not common to find machines compatible with STEP$\mathrm{NC}$, and although this format is beginning to be available in some modern machining centres, the price of a machine of this type is very high, making the entry of these modern systems difficult and with more advantages in a sector where renovation is not easy or frequent.
Analysing all this information, it can be seen that the introduction of STEP-NC in this sector is going to be a necessity in the next few years, and that changing the machinery to support all this information would require a quite important investment. An alternative would be to adapt the machinery that companies currently have, so that they can operate and use the advantages of STEP-NC.

This adaptation can go through several phases. Initially, a computer connected directly to the machine could be employed to use the information received in STEP-NC format, calculate the machining tool path (if only the strategy is defined) and generate a file compatible with the machine. A dedicated hardware device may be used to calculate the path, but cloud computing may also be used to do it [20], [21]. As a final part, a retrofitting of the current machines with a new control that supports STEP-NC could be carried out. This would require converting a "dumb" control, only capable of following a list of points, into a control capable of understanding geometry, and since the file would indicate what to do, it would have to calculate the path and decide how to move it to machine and obtain the correct result. This means that the control has to be smart and, therefore, it will require much more computing power.

\subsection{A review of the current machine features}

In order to evaluate the proposal from an economic point of view, an initial study has been carried out on the environment to which the proposed solution would be targeted. Specifically, the $\mathrm{CAD} / \mathrm{CAM} / \mathrm{CNC}$ solutions of several companies in the sector have been analysed in order to assess whether the viability of the proposal is realistic.

\begin{tabular}{|c|c|c|c|c|}
\hline Machine & Picture & Toolpath & Format & Step-NC compatible \\
\hline $\begin{array}{l}\text { Leather cutting } \\
\text { machine }\end{array}$ & & & $\begin{array}{c}\text { DXF, HPGL, ... } \\
\text { Normally open } \\
\text { format }\end{array}$ & NO \\
\hline 3 axis $\mathrm{CNC}$ & & & $\begin{array}{l}\text { G-code } \\
\text { Open }\end{array}$ & NO \\
\hline Lathe (lasts) & & & $\begin{array}{c}\text { FRV } \\
\text { Proprietary format }\end{array}$ & NO \\
\hline Sewing machine & & & Proprietary format & $\mathrm{NO}$ \\
\hline
\end{tabular}




\begin{tabular}{|l|l|l|l|}
\hline $\begin{array}{l}\text { Pounding \& roughing } \\
\text { machine }\end{array}$ & Proprietary format & NO \\
\hline 3D printer & & $\begin{array}{c}\text { G-code } \\
\text { Open }\end{array}$ & NO \\
\hline
\end{tabular}

Table 1: Different machines used in footwear production

As can be seen in Table 1, some of the machines used to manufacture different components of a shoe are shown. Each of them uses a different format and most of them use proprietary formats, none of them being compatible with the Step-NC standard.

\subsection{Used geometries and toolpaths in footwear CAD/CAM software}

Although this study focuses on the machining part, it should not be forgotten that the CAD information for each of the different parts/pieces that make up a shoe, and which are used for its manufacture, must also be included. For this purpose, the main parts and components used for their manufacture are analysed, as well as the way in which they are represented in the STEP-NC.

Shoemakers start the shoe design with a foot model of the population. In the case of an orthopaedic shoe, a prescription will also be issued by a podiatrist or a similar professional.

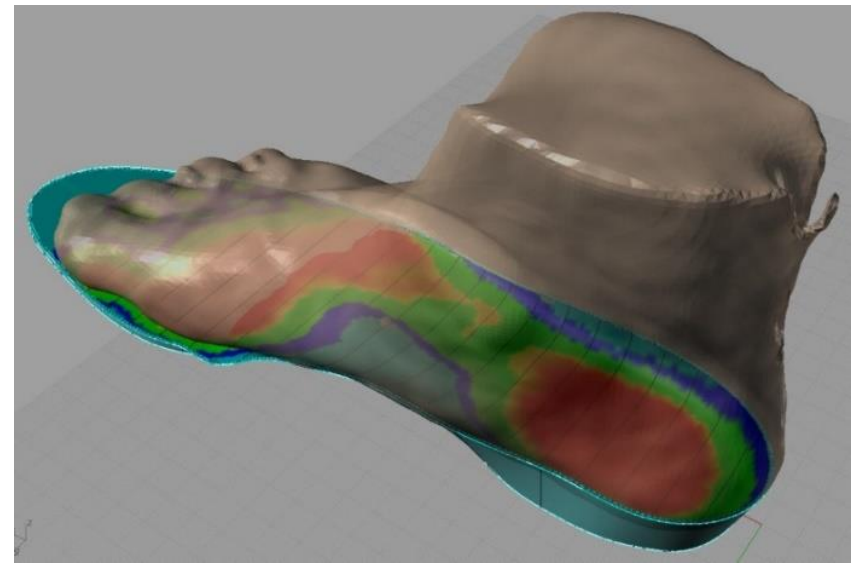

Fig 2: Foot, plantar pressures map and insole

From this information, a last will be fit to this foot (see Fig 3) [22]. With the last, the foot, the plantar pressures map and the prescription of a specialist if necessary, the insole will be designed (see Fig 2).
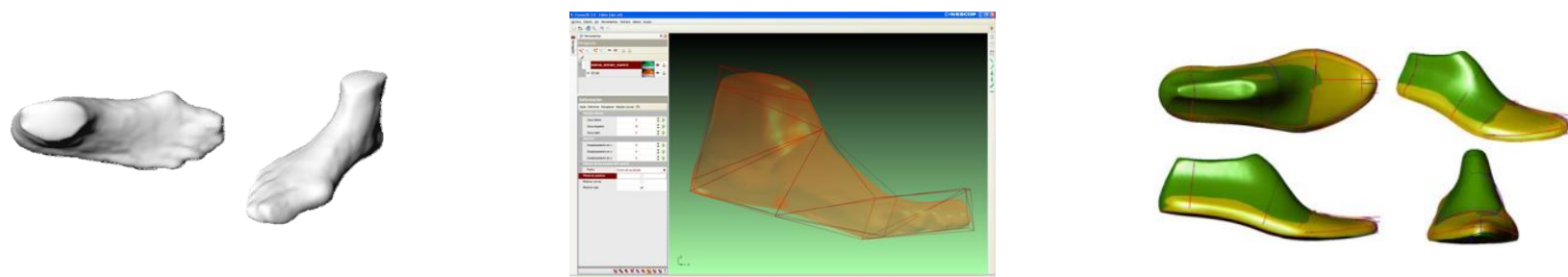

Fig 3: Digitized foot, adjusting the last to the foot and the result 


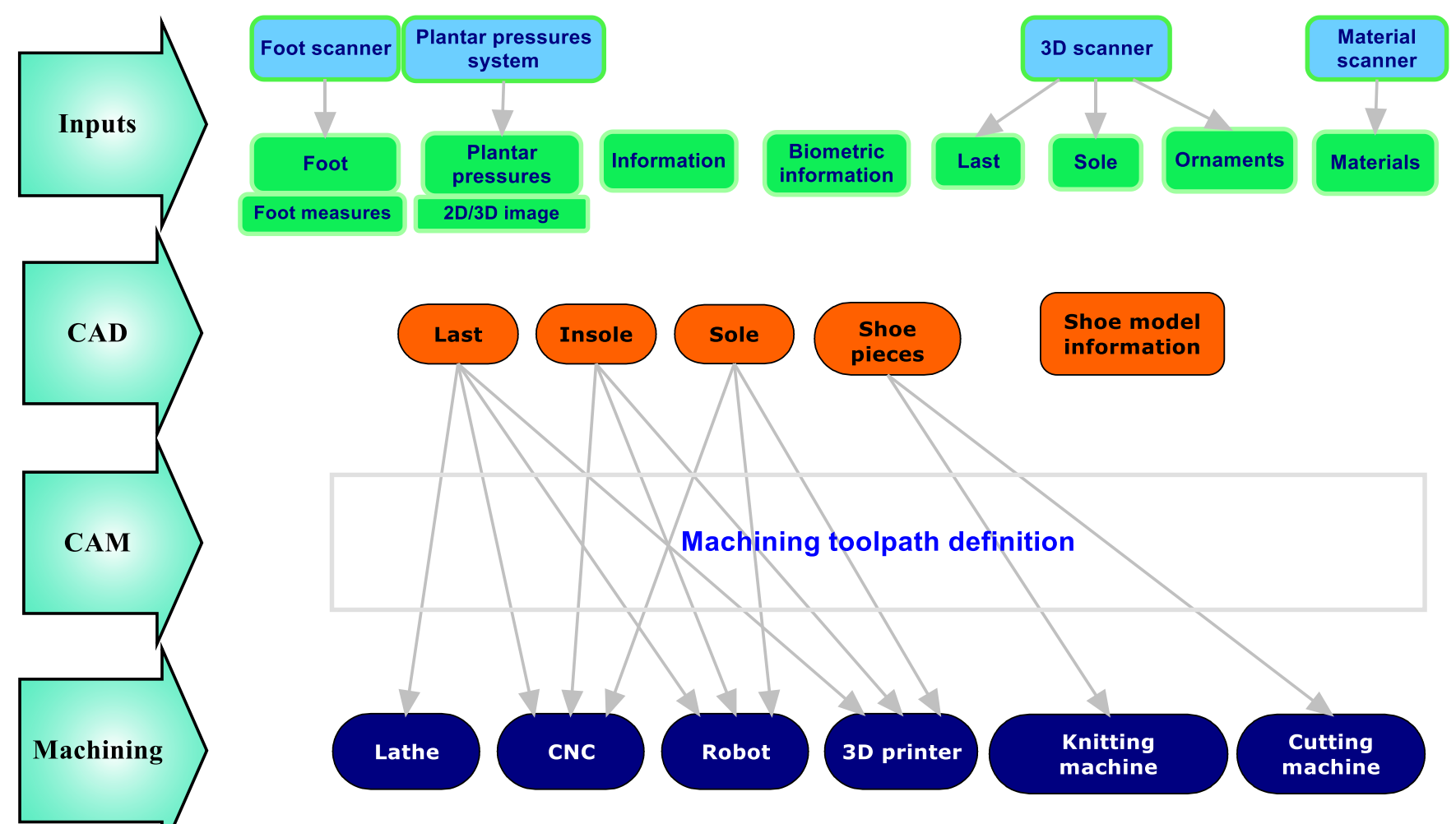

Fig 4: Footwear manufacturing process

The footwear manufacturing process (see Fig 4) starts taking the shoe last as a basis, and the model will be designed (or an existing one will be adjusted). As a result, the different pieces, linings, midsole, counter, etc., will be available. These components will vary according to the type of footwear to be manufactured (sports shoe, casual shoe, formal shoe, etc.).

Next, the last already dressed is needed (incorporating pieces, sole, etc.) to be able to design the sole or, in general, the component with which the shoe is going to rest on the ground. It may be a complete sole, a heel, a wedge, a platform or even, in some cases, a combination of several of these elements.

The different components that make up a shoe can be represented or designed using CAD tools. These tools will define the elements in different ways, and these will allow different operations to be carried out with them. It is important to take into account that shoes will have different sizes and a right/left shoe model is needed so as to design every component.

What kind of geometry does each element represent?

- Digitized foot. When a foot is digitized (see Fig 5), a point cloud is usually obtained, and from this point cloud a mesh is constructed.

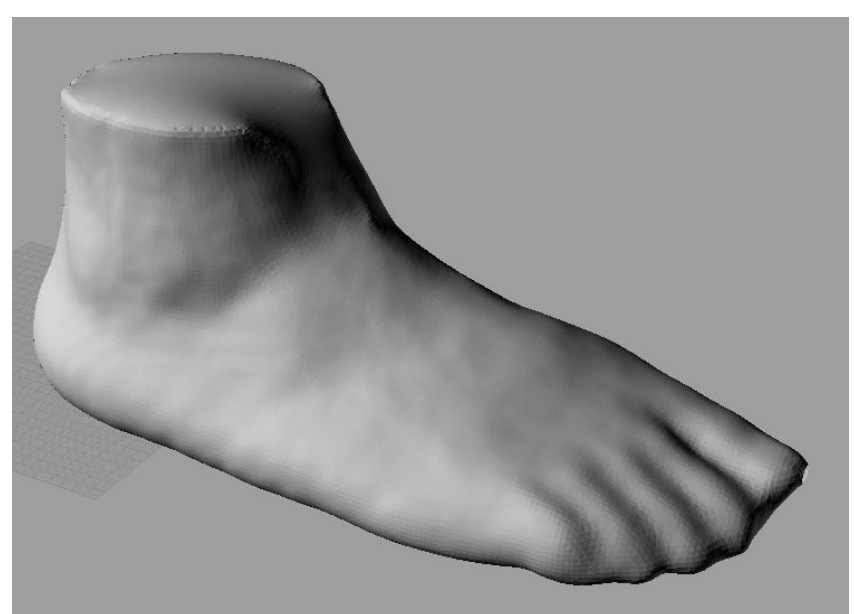

Fig 5: Rebuilt mesh from the digitization of a foot

- Shoe last. It is usually represented as a NURBS surface (see Fig 6).

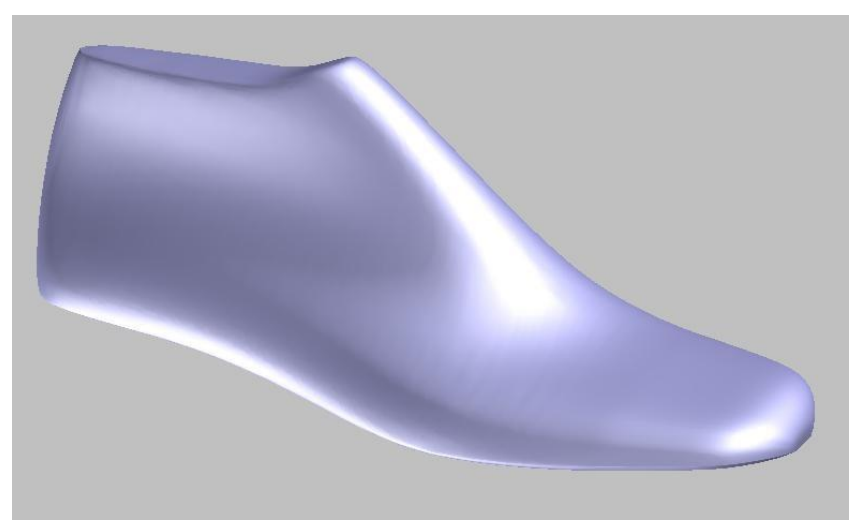

Fig 6: Surface of a last 
The last is one of the main components in the shoe manufacturing and it is mechanized in a turning lathe [23], [24].

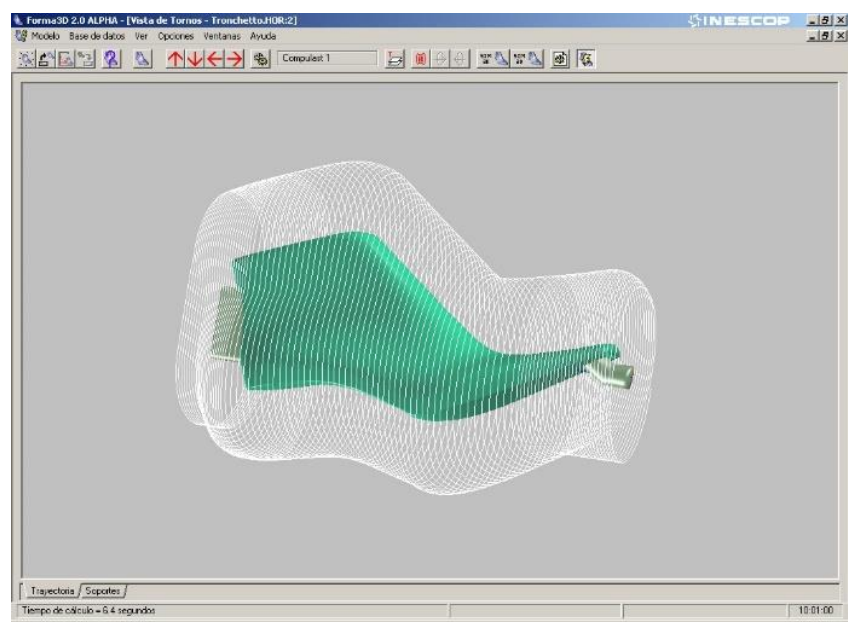

Fig 7:Finishing toolpath of a shoe last

The machining of the last starts with a pre-formed block, which has to be roughened with several toolpaths, and it ends with a finishing toolpath (see Fig 7). The result produces a plastic object (see Fig 8) that will be used as the "mould" for the shoe.

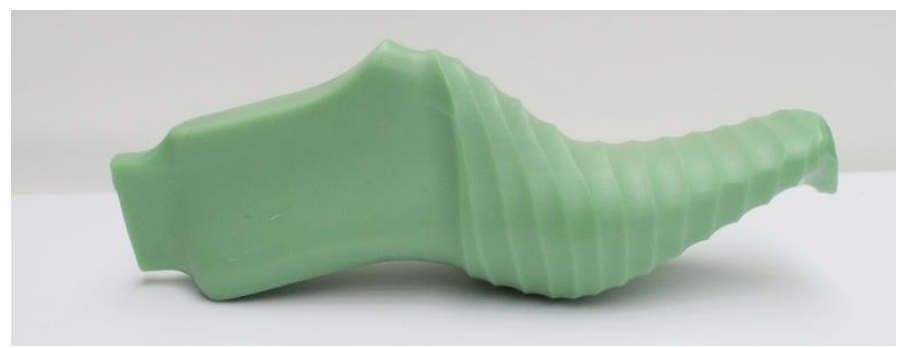

Fig 8: Mechanized last. Left part roughed and finished; right part roughed

Nowadays the use of 3D printed lasts (see Fig 9) to manufacture shoe prototypes is steadily increasing. This process allows to introduce modifications in a fast way. Depending on the parameters used to print the last, it could be used perfectly to produce a small set of shoes [25]. The thickness of the external wall and the internal structure, as well as the material, must be defined in an appropriate way and the elements necessary for the manufacture of shoes (tubes, joints, ...) must be incorporated into the design. During the shoe manufacturing process, the last will be subjected to different pressure and thermal stress processes (cold and hot).

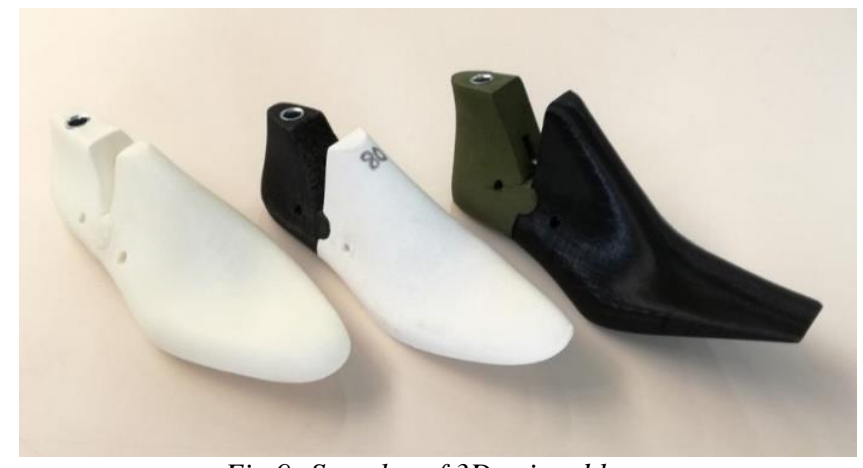

Fig 9: Samples of 3D printed lasts
- Insoles. It is represented as a polysurface or a mesh.

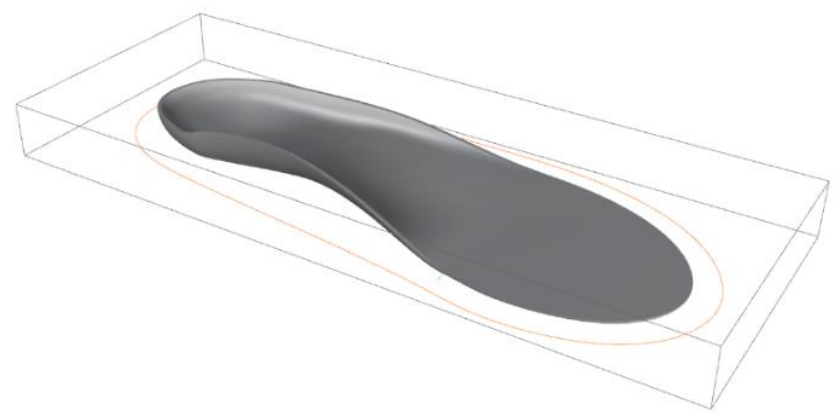

Fig 10: Insole

The insole (see Fig 10) could be customized or not. Most of the shoes use a standard 2D insole, but it is increasing the use of 3D insoles to improve comfort. This kind of insoles can be mechanized in CNC milling centres, producing directly the customized insole or the mould for mass production of insoles.
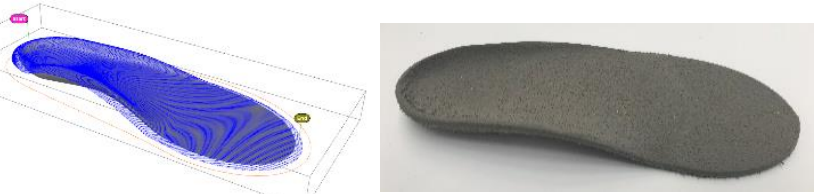

Fig 11: Left: insole's milling toolpath; Right: milled insole

Typical toolpaths to mechanize the insole in a milling machine are common roughing and finishing strategies (see Fig 11), without special options. It is also available the option to produce insoles using 3D printers (see Fig 12) [26].

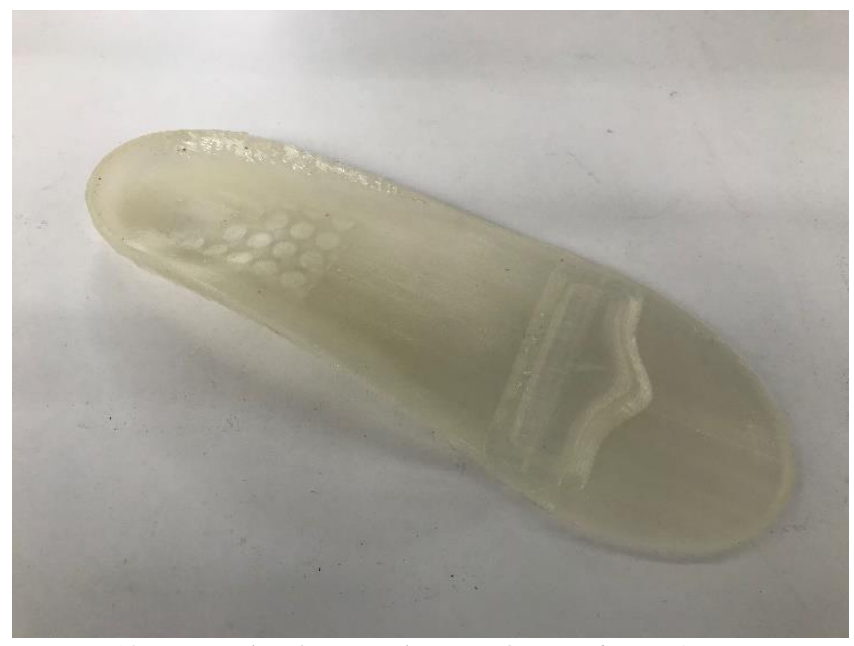

Fig 12: Example of an insole manufactured on a 3D printer

- Upper pieces. These parts are 2D curves (polylines, NURBS, B-Spline). Moreover, if the pieces have been designed from the 3D last and its flattening, surely the pieces will be in 3D, represented by polysurfaces (see Fig 13). 


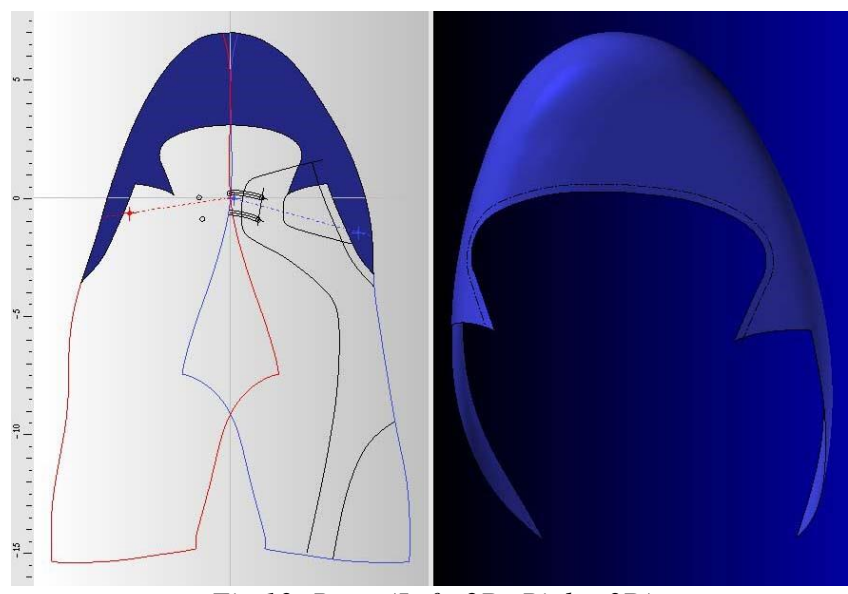

Fig 13: Parts (Left: 2D; Right: 3D)

These are produced by cutting leather or different synthetic materials on an automatic cutting table (see Fig 14). These kind of machines need a $2 \mathrm{D}$ toolpath and the pieces must be positioned properly in order to optimize the use of material.

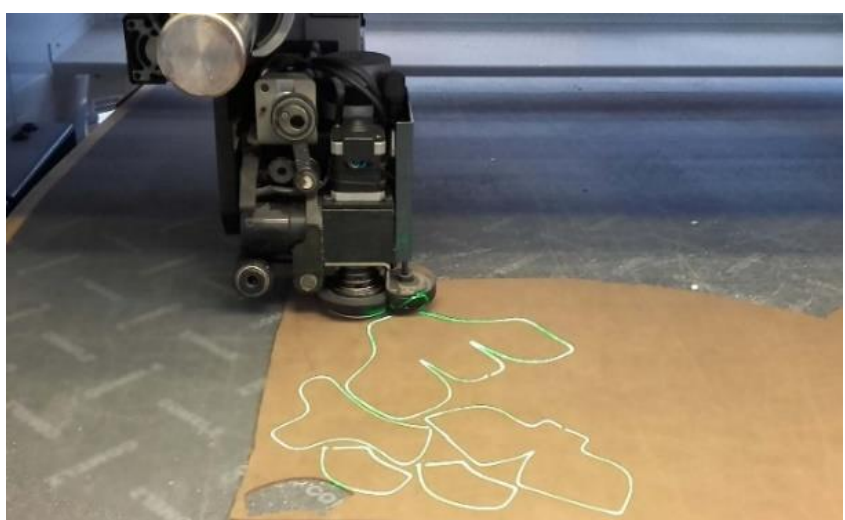

Fig 14: Automatic cutting machine projecting pieces

- Outsole / Heel / Wedge / Platform. They are usually represented as polysurfaces, although in some cases they are represented as meshes (see Fig 15).
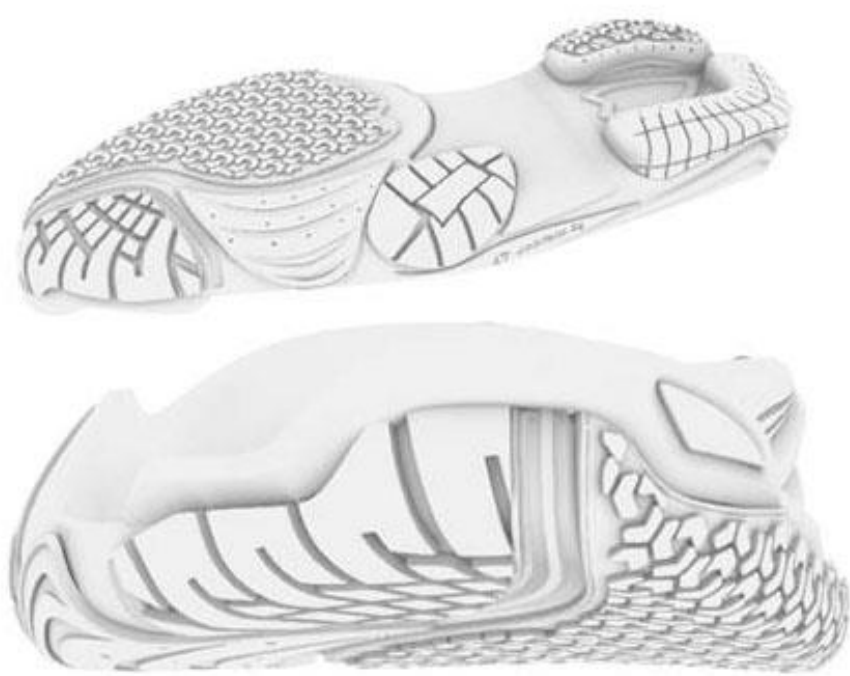

Fig 15: Footwear outsole designed with INESCOP Icad3DP

These components are not usually mechanized directly, unless the objective is the manufacture of a prototype, or in the case of heels, an aluminium male is machined (see Fig 16), and with that male, a mould will be created by a casting process.

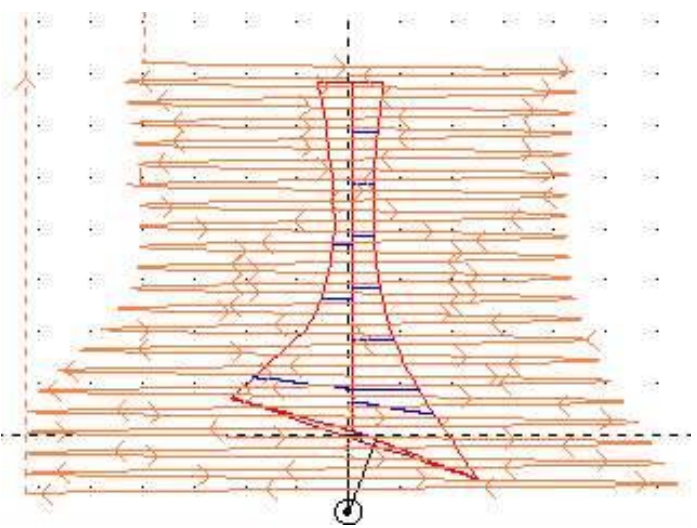

Fig 16: Milling toolpath of a heel

For the production of soles, designing a mould and mechanizing it in a CNC milling machine is mandatory.
Classical milling strategies are needed to mechanize the moulds.

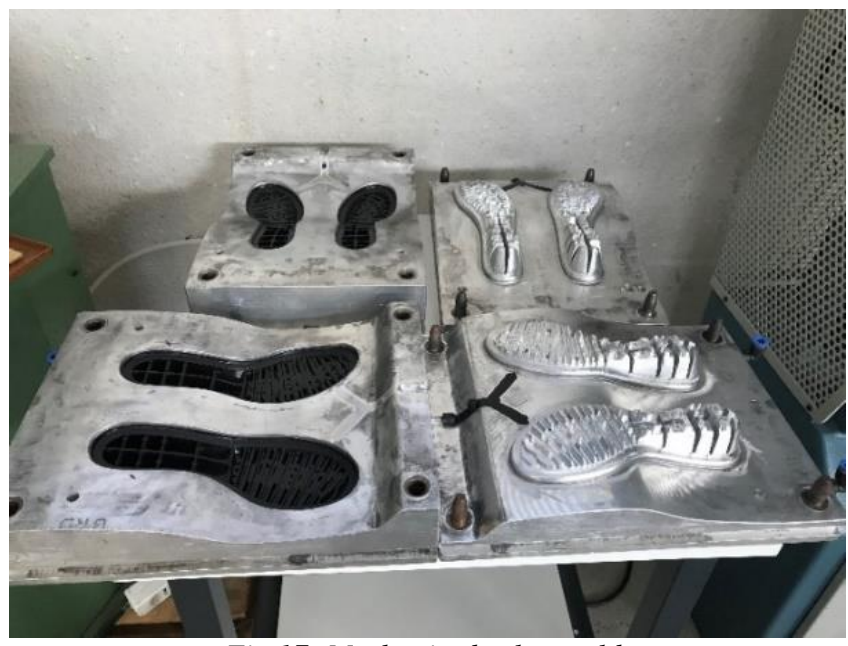

Fig 17: Mechanized sole moulds

The machining of an outsole mould (see Fig 17) is one of the more complex and expensive tasks: many paths and 
tolls are required, so it is very common to make prototypes using 3D printers (see Fig 18) to reduce costs.

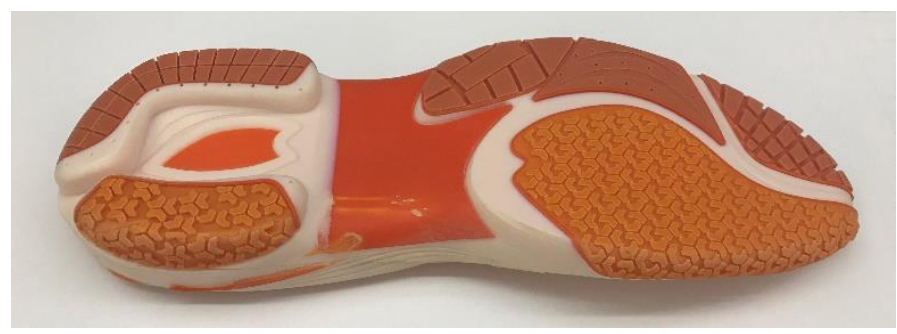

Fig 18: Footwear sole printed in $3 D$

The elements described are the main ones used in footwear manufacturing, but there are more components and machines, whose number varies according to the shoe model. Most of these elements can be represented and manufactured in the same way that the components showed above.

For the complete shoe, it is necessary to use additive manufacturing technology for producing fast prototypes (see Fig 19) to help manufactures decide some details before the production phase. All the elements are needed to print a $3 \mathrm{D}$ prototype with all kind of details.

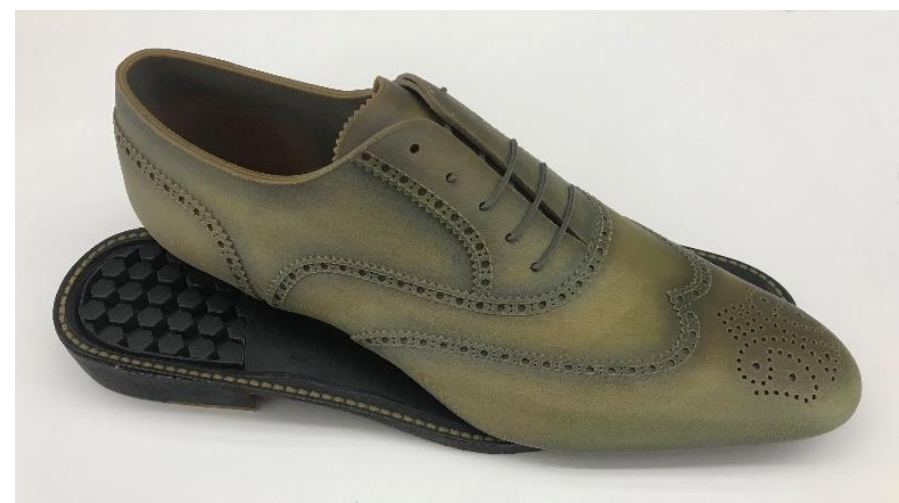

Fig 19: Shoe prototype produced in a $3 D$ printer

All the elements that make up the shoe are related, and the introduction of a modification in one of them leads to the modification of the rest of them (mainly if the modification affects the shoe last). Modifying any element involves changing the toolpaths to machine it. It is necessary to recalculate the paths, generate the files, and send them to the corresponding machine. Sometimes, the designer draws a component impossible to mechanize, and during the machining phase it is necessary to modify the geometries. The footwear industry uses many manual machines because of the complexity of generating toolpaths automatically. This is due to the high frequency of changes in models and their geometries, which makes it difficult to establish a relationship between the CAD phase and the manufacturing phase. Therefore, the introduction of STEP-NC could improve the footwear manufacturing process in this concern.

\section{Approach to integrate STEP-NC in the footwear industry}

From the software point of view, STEP-NC can contain the geometries mentioned above, but the greater complexity would remain in the machinery. Due to the diversity of machines used in different machinery manufactures, in which everyone has their different way of operating and format, most of them use proprietary formats, as shown in Table 1 . It is very unlikely that machinery manufacturers adopt STEP-NC in a first step.

There are 3 different ways to implement STEP-NC in a machine (see Fig 20), widely described in the bibliography [18], [27]-[29]:

- Conventional control. Incorporating STEP-NC to conventional controls through post-processing. In this case, existing controls can be used without modification. This type of control reads the STEP-NC code and generate files for legacy machines.

- New machine control. These controls have an integrated STEP-NC interpreter, so the programmed working steps are executed by the $\mathrm{CNC}$ kernel with the ability to generate trajectories.

- New intelligent control. This type of control is the most promising and is capable of performing machining tasks smartly and autonomously, based on the information contained in the STEP-NC file. Some examples of intelligent functions are: automatic feature recognition, automatic path generation (collision free) including control of approach and separation, automatic tool selection, automatic selection of cutting conditions, status monitoring, and status and result feedback.

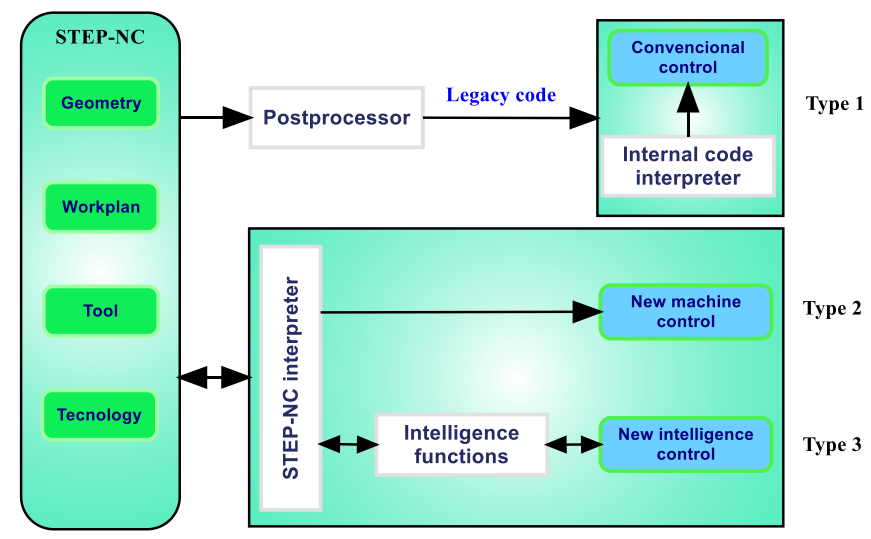

Fig 20: STEP-NC controls

The ideal situation is to implement a new intelligent control, although a progressive implementation would be the most suitable. Initially, a module could be developed to translate STEP-NC into native machine code, and then expand and incorporate features into it until smart control is achieved.

The first step to achieve this would be having CAD/CAM tools that would allow to integrate all the geometric components mentioned before, with their corresponding integrated machining orders according to the standard. Initially, these files would contain the toolpath information, so that only a translation from the STEP-NC format to the machine's native format would be necessary for machining the different parts. Thus, a type 1machine is achieved. 


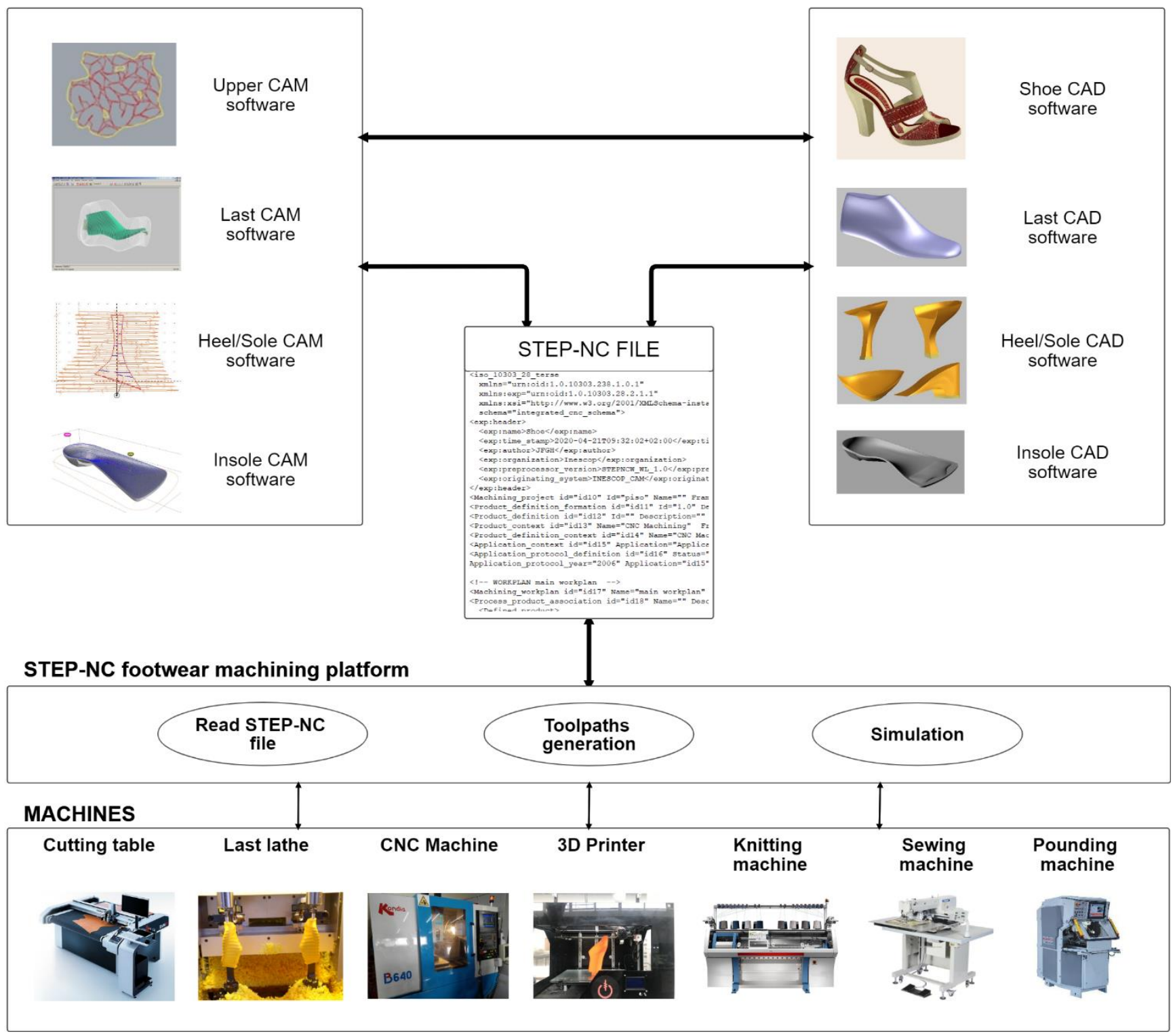

Fig 21: Relations of Step-NC file with software and machines

The next step would be to provide the machine with the required calculation capacity, thus removing this capacity from the CAM phase, which would only define the strategy and the appropriated parameters (strategy type, tool definition, steps...). This is the phase in which more computing power would be required in the machine and, for this reason, the initial approach would be to introduce systems for computing speed up through dedicated hardware, which would mean performing computing into devices such as FPGAs [23], [30], [31] or GPUs [32]. This could also be done through cloud computing [20].

The last step would be to have a smart system, which would be able to determine the best tool to perform each operation and adjust the trajectory according to the working conditions. An important aspect would be to detect if the machine has broken down during the machining process and change it at run time. To this end, it is important that the path calculation process is carried out quickly at the run time. It would be useless to have the path completely calculated and have the tool break at some point during the machining operation, because at that moment all the calculations would have to be recomputed, which could result in inactivity time in the machining process.
Once the different options that can be used for the implementation of STEP-NC have been defined, and given the variety and complexity of the machinery used, it is proposed to use a STEP-NC footwear machining platform. This platform (see Fig 21) acts as a bridge between STEP-NC files and the different machines.

This platform aims to:

- Focus on the footwear sector, taking into account their special needs: sizes, right/left foot, parameter optimization and simplification.

- Necessary flexibility in Industry 4.0 with the use of old machinery.

- Intelligent monitoring [33].

- Distributed/cloud manufacturing [11], [34], [35].

- Inspection and quality specification [36].

- $\quad$ Process planning (CAPP) [6], [37], [38].

- Closed loop machining to improve the data feedback [7], [27], [39], [40]. 
Not every one of these characteristics can be implemented in a type 1 implementation (see Fig 20), but they are a motivation for the implementation of this technology in new machines.

\section{Experimental test}

In order to test the feasibility of the proposed platform, two tests have been carried out: (1) machining a last in a lathe and (2) machining a heel in a milling machine; both elements should be manufactured in well-differentiated machines since they are relevant in the footwear industry.

\section{- Last manufacturing}

To mechanize a last, a module has been added to Inescop's software IcadFor to be able to generate data in Step-NC format. Using the CAM interface of the software, a file containing the machining work plan can be generated. To do this, the STEP-NC Write library from Step tools inc. [41] has been used. This library simply allows the export of Step-NC files in $\mathrm{CC} 1$ format. However, for these tests it has not been possible to include the geometry in the same file. To generate the different working steps, it is necessary to add the back and front support to the geometry of the last, in order to be able to machine it properly on a lathe, and to define the different steps according to the zone. In this example, 180 points per section have been used, with a main step of $1 \mathrm{~mm}$ and $0.5 \mathrm{~mm}$ in the heel and toe area $(20 \mathrm{~mm})$ to obtain better resolution in these areas (see Fig 22).

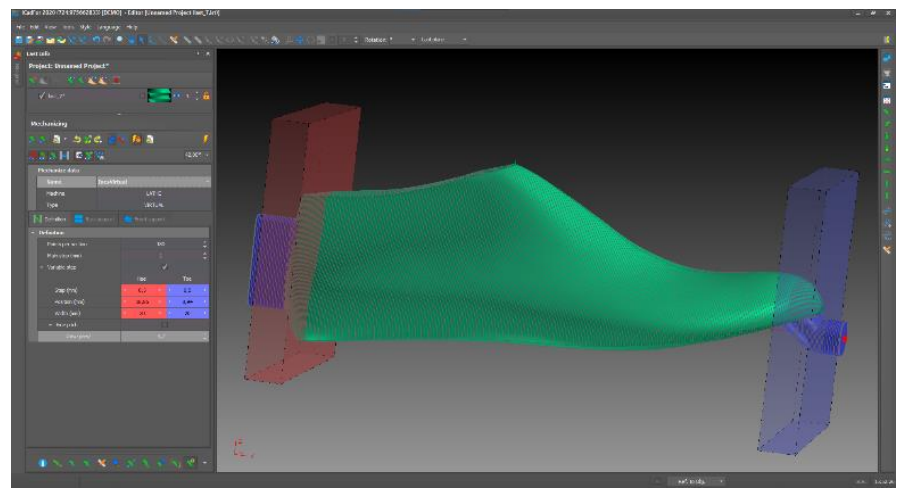

Fig 22: CAM parameters

Work plan and working steps definition. The file contains only one work plan with different working steps:

\section{○ Pre-roughing \\ $\circ$ Roughing \\ ○ Finishing}

An application has been developed to import the Step-NC file. Using a simple definition of tools and parameters, the application calculates the adequate toolpath for the machine, and generates the file for classical last lathes (.dg1 and .mod) (see Fig 23).

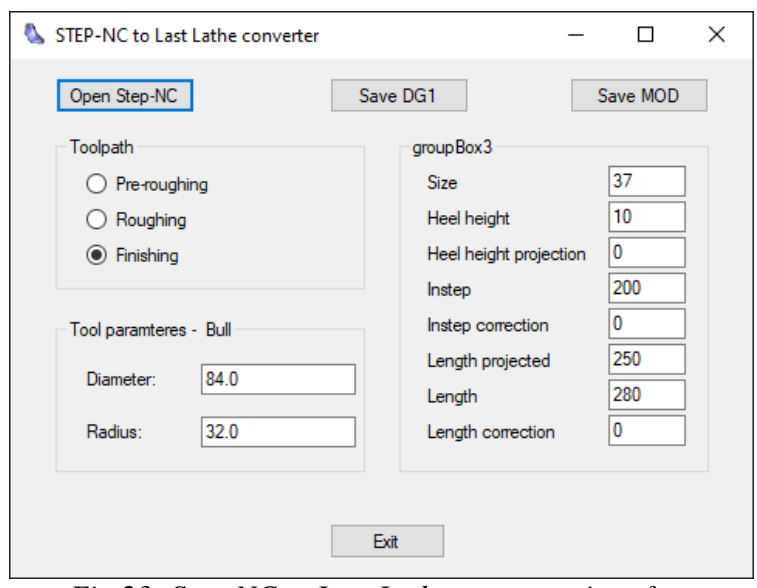

Fig 23: Step-NC to Last Lathe converter interface

- Heel manufacturing

To mechanize a heel made of aluminium (see result in Fig 27) and to create afterwards a mould with a casting process, we have used IcadCAM, a software developed by Inescop to generate milling toolpaths. This software includes some pre-created toolpaths to allow heel makers to create a heel in an easy way without using complex mechanizing parameters, as heels usually have a similar geometry. The best way to mill a heel is using a roughing strategy (see Fig 24 left) to adjust the heel height, and afterwards, most of the heels can be made using a spiral with a small step (see Fig 24 right). Toolpath parameters depend on the used tool; one of the most used tools is a bull with a $75 \mathrm{~mm}$ big radius and a $4 \mathrm{~mm}$-cut radius.
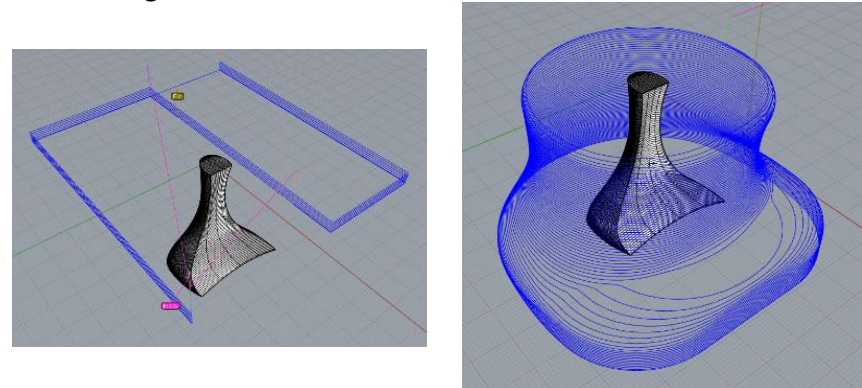

Fig 24: Machining toolpaths for a heel. Roughing (left) and finishing (right)

In this example we have used a $1 \mathrm{~mm}$-step for the roughing toolpath and a $0.3 \mathrm{~mm}$-step for the finishing toolpath.

This software has the property of generating nc files for many different milling machines, therefore, for testing the STEP-NC, we have added a new kind of machine to generate STEP-NC files. As in the example provided for the last, we have used the same STEP-NC Write library.

Work plan and working steps definition. The file contains a work plan with two working steps: one for roughing and the other for finishing.

With the same philosophy from the previous example, a simple application has been created to convert STEP-NC files to NC files in G-code format. No calculation module has been integrated in this test application. The STEP-NC file contains the toolpath points and the application simply reads the points and 
converts them to G-code format in order to send them to the machine. This application can postprocess the code to many different machines (see Fig 25), however, a Kondia B640 has been used together with Heidenhain 430 control.

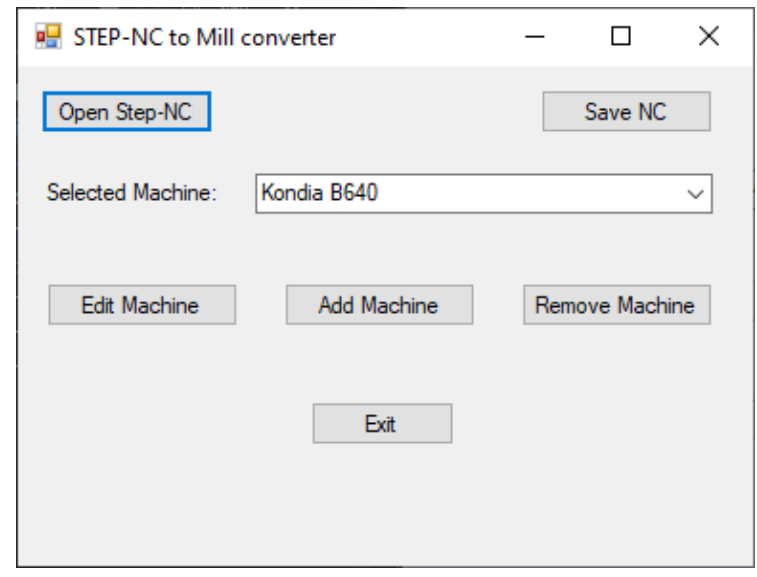

Fig 25: Step-NC to Mill converter interface

Some other controls have been integrated in this application. In the machine configuration view, the user can select the appropriate control and other parameters to generate the file correctly (see Fig 26).

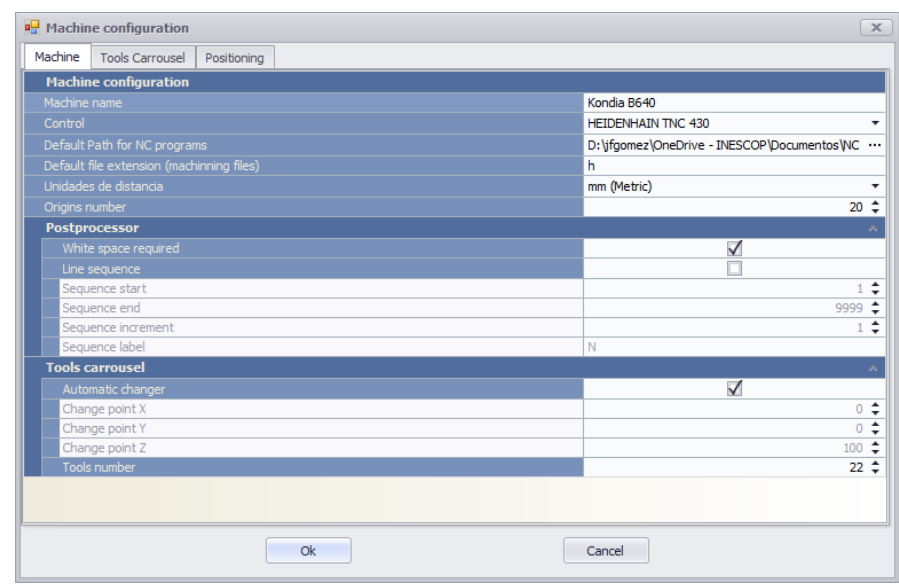

Fig 26: Machine configuration options

STEP-NC files have a complicated structure difficult to understand just at simple sight, without using an algorithm. Thus, we decided not to include any fragment of the file in this paper.

The main advantages of using Step-NC files in this case is the opportunity of generating files for different machines in a simple way, using the Step-NC as the source.

Step-NC AP238 has been designed for the integration of $\mathrm{CAD}, \mathrm{CAM}$ and manufacturing. This means that implementing all the functionalities is quite complex for the approach of this paper.

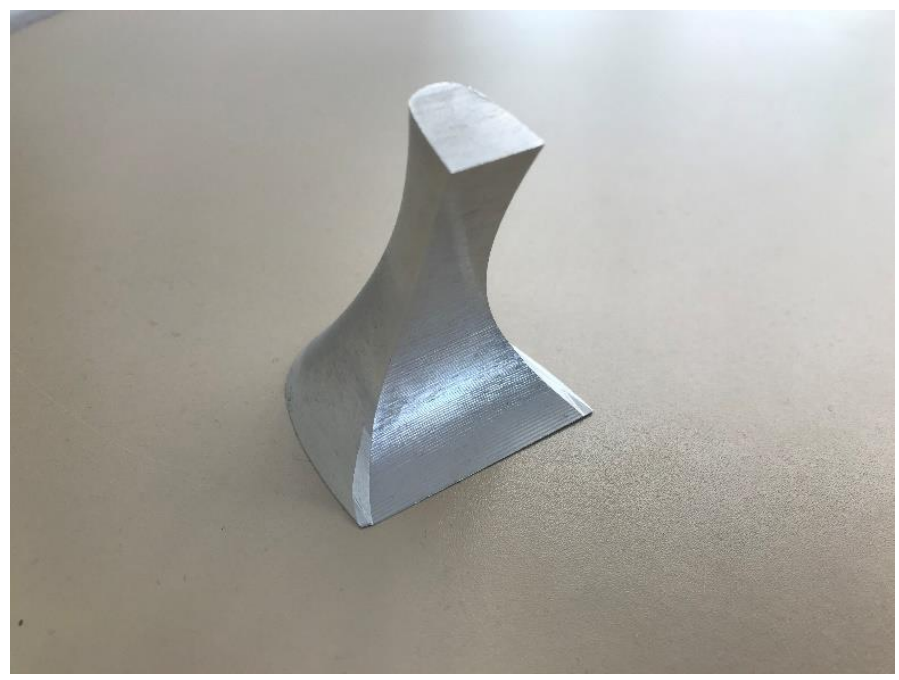

Fig 27: The heel milled in aluminium using a Kondia B640

\section{Conclusions}

In this paper, a platform has been proposed as a solution to adopt STEP-NC in the footwear industry for improvement of the shoe manufacturing process. Nowadays, new paradigms in industry, such as Industry 4.0 or smart factories, must also have an impact on traditional sectors, such as footwear, where most companies are SMEs and cannot afford large investments in technology.

The need for flexible production lines to adapt manufacturing to short production series and rapid changes in fashion make it difficult to apply new technologies.

This approach allows the use of legacy machinery, and additionally, improves the software layer interconnecting different $\mathrm{CAD}$ and CAM software applications with the machining level. Therefore, it can be used as a starting point to introduce changes in footwear machinery.

For future research, it is proposed to study in more detail the numerical controls of the described machinery, with the aim of developing intelligent controls that allow such machinery to generate complex toolpaths by itself, as well as to recover information from the sensors, thus trying to close the footwear manufacturing loop with the STEP-NC standard.

\section{References}

[1] P. Mueller and Y. T. Hyun, 'STEP-Compliant Data Interface for Numerical Controls (STEP-NC). STEP-NC Final Report'. Espirit Project EP 29708, Nov. 2001, [Online]. Available: http://www.step-nc.org/data/eu1_final_report.pdf.

[2] STEP-NC, 'STEP-NC official web page', Jan. 12, 2007. www.step-nc.org.

[3] ISO 10303-238, 'ISO10303-238 Industrial automation systems and integration - product data representation and exchange part 238: application protocol: application interpreted model for computerized numerical controllers.' 2007.

[4] ISO/TC 184/SC 4 Industrial data, 'ISO/DIS 10303-238 (second edition), Industrial automation systems and integration Product data representation and exchange - Part 238: Application protocol: Model based integrated manufacturing'. ISO, 2019, [Online]. Available:

https://www.iso.org/cms/render/live/en/sites/isoorg/contents/da ta/standard/07/20/72030.html.

[5] ISO14649-11, 'ISO14649-11 Industrial automation systems and integration - physical device control - data model for 
computerized numerical controllers - part 11: process data for milling.' 2004.

[6] J. Pobozniak and S. Sobieski, 'Extension of STEP-NC Data Structure to Represent Manufacturing Process Structure in CAPP System', Procedia Manuf., vol. 11, pp. 1692-1699, Jan. 2017, doi: 10.1016/j.promfg.2017.07.294.

[7] C. I. Riaño and A. J. Álvares, 'Feedback strategy for closedloop inspection based on STEP-NC', J. Phys. Conf. Ser., vol. 1065 , no. 8, p. 082014, Aug. 2018, doi: 10.1088/1742$6596 / 1065 / 8 / 082014$

[8] ISO 6983, 'ISO 6983-1:2009 Numerical control of machinesprogram format and definition of address words - Part1: data format for positioning, line motion and contouring control systems', ISO, 2009.

https://www.iso.org/cms/render/live/en/sites/isoorg/contents/da ta/standard/03/46/34608.html.

[9] EIA, 'EIA494B: 32 Bit Binary CL (BCL) and 7 Bit ASCII CL (ACL) Exchange Input Format for Numerically Controlled Machines - SAE International', 1992. https://www.sae.org/standards/content/eia494b/.

[10] T. Kramer, 'Evaluating manufacturing machine control language standards: An implementer's view', Proc. 2007 Workshop Perform. Metr. Intell. Syst., pp. 267-274, Jan. 2007, doi: 10.1145/1660877.1660916.

[11] X. W. Xu, Lihui Wang, and Yiming Rong, 'STEP-NC and function blocks for interoperable manufacturing', IEEE Trans. Autom. Sci. Eng., vol. 3, no. 3, pp. 297-308, Jul. 2006, doi: 10.1109/TASE.2005.862147.

[12] Heidenhain, 'Heidenhain Conversational Programming'. Jul. 1999, [Online]. Available: https://content.heidenhain.de/doku/tnc_guide/pdf_files/TNC40 0/280472-xx/bhb/322_938-24.pdf.

[13] CEN/ISSS, 'CWA 15043 Proposal for a XML-based format for storage and exchange of design data in the footwear industry'. Jul. 2004.

[14] M. Rauch, R. Laguionie, J.-Y. Hascoët, and X. Xu, 'Enhancing CNC Manufacturing Interoperability with STEP-NC', 2010.

[15] E. Rodriguez and A. Alvares, 'A STEP-NC implementation approach for additive manufacturing', Procedia Manuf., vol. 38, pp. 9-16, Jan. 2019, doi: 10.1016/j.promfg.2020.01.002.

[16] S. Zivanovic, N. Slavkovic, and D. Milutinovic, 'An approach for applying STEP-NC in robot machining', Robot. Comput.Integr. Manuf., vol. 49, pp. 361-373, Feb. 2018, doi: 10.1016/j.rcim.2017.08.009.

[17] B. Solvang, L. K. Refsahl, and G. Sziebig, 'STEP-NC Based Industrial Robot CAM System', IFAC Proc. Vol., vol. 42, no. 16, pp. 245-250, Jan. 2009, doi: 10.3182/20090909-4-JP2010.00043

[18] W. Xiao, L. Zheng, J. Huan, and P. Lei, ‘A complete CAD/CAM/CNC solution for STEP-compliant manufacturing', Robot. Comput.-Integr. Manuf., vol. 31, pp. 1-10, Feb. 2015, doi: 10.1016/j.rcim.2014.06.003.

[19] J. Garrido Campos and R. Marín Martín, 'Modelling and implementing circular sawblade stone cutting processes in STEP-NC', Robot. Comput.-Integr. Manuf., vol. 26, no. 6, pp. 602-609, Dec. 2010, doi: 10.1016/j.rcim.2010.06.027.

[20] G. M. Martinov, A. B. Ljubimov, and L. I. Martinova, 'From classic CNC systems to cloud-based technology and back', Robot. Comput.-Integr. Manuf., vol. 63, p. 101927, Jun. 2020, doi: 10.1016/j.rcim.2019.101927.

[21] M. Mourad, A. Nassehi, and D. Schaefer, 'Interoperability as a Key Enabler for Manufacturing in the Cloud', Procedia CIRP, vol. 52, pp. 30-34, Jan. 2016, doi: 10.1016/j.procir.2016.07.051.

[22] M. Davia-Aracil, 'Modelado geométrico biodeformable del pie. Aplicación a la fabricación de calzado personalizado', Universidad de Alicante-Inescop, Inescop, 2011.

[23] A. Jimeno, J. L. Sánchez, H. Mora, J. Mora, and J. M. GarcíaChamizo, 'FPGA-based tool path computation: An application for shoe last machining on CNC lathes', Comput. Ind., vol. 57, no. 2, pp. 103-111, Feb. 2006, doi:

10.1016/j.compind.2005.05.004.
[24] S. Cuenca-Asensi, A. Martínez-Álvarez, A. Jimeno-Morenilla, and J.-L. Sanchez-Romero, A hardware/software architecture for tool path computation: an application to turning lathe machining. IEEE, 2007.

[25] INESCOP, 'ADAPT3D - Metodologías de impresión 3D adaptativas para el desarrollo de hormas y fabricación de prototipos de calzado', Deliverable, 2018. [Online]. Available: https://www.inescop.es/es/inescop/actividad/proyectos-i-di/proyectos-i-d-i-ivace/ivace/18-2018/209-adapt3d.

[26] M. Davia-Aracil, J. J. Hinojo-Pérez, A. Jimeno-Morenilla, and H. Mora-Mora, '3D printing of functional anatomical insoles', Comput. Ind., vol. 95, pp. 38-53, Feb. 2018, doi: 10.1016/j.compind.2017.12.001.

[27] P. Hu, Z. Han, H. Fu, and D. Han, 'Architecture and implementation of closed-loop machining system based on open STEP-NC controller', Int. J. Adv. Manuf. Technol., vol. 83, no. 5, pp. 1361-1375, Mar. 2016, doi: 10.1007/s00170015-7631-z.

[28] M. Rauch, R. Laguionie, J.-Y. Hascoet, and S.-H. Suh, 'An advanced STEP-NC controller for intelligent machining processes', Robot. Comput.-Integr. Manuf., vol. 28, no. 3, pp. 375-384, Jun. 2012, doi: 10.1016/j.rcim.2011.11.001.

[29] S. H. Suh, B. E. Lee, D. H. Chung, and S. U. Cheon, 'Architecture and implementation of a shop-floor programming system for STEP-compliant CNC', Comput.-Aided Des., vol. 35, no. 12, pp. 1069-1083, Oct. 2003, doi: 10.1016/S00104485(02)00179-3.

[30] A. Jimeno-Morenilla, A. Martinez, S. Cuenca, and J. L. Sanchez-Romero, 'Accelerating tool path computing in CAD/CAM: A FPGA architecture for turning lathe machining', in 2007 International Conference on Field Programmable Logic and Applications, Aug. 2007, pp. 702705, doi: 10.1109/FPL.2007.4380749.

[31] S. Cuenca, A. Jimeno-Morenilla, A. Martínez, and R. Maestre, 'Hardware approach to tool path computation for STEP-NC enabled CNC: A case study of turning operations', Comput. Ind., vol. 62, no. 5, pp. 509-518, Jun. 2011, doi: 10.1016/j.compind.2011.02.001.

[32] V. Morell-Giménez, A. Jimeno-Morenilla, and J. GarcíaRodríguez, 'Efficient tool path computation using multi-core GPUs', Comput. Ind., vol. 64, no. 1, pp. 50-56, Jan. 2013, doi: 10.1016/j.compind.2012.09.009.

[33] W. Liu, C. Kong, Q. Niu, J. Jiang, and X. Zhou, 'A method of $\mathrm{NC}$ machine tools intelligent monitoring system in smart factories', Robot. Comput.-Integr. Manuf., vol. 61, p. 101842, Jul. 2019, doi: 10.1016/j.rcim.2019.101842.

[34] M. H. Mourad, A. Nassehi, D. Schaefer, and S. T. Newman, 'Assessment of interoperability in cloud manufacturing', Robot. Comput.-Integr. Manuf., vol. 61, p. 101832, Feb. 2020, doi: 10.1016/j.rcim.2019.101832.

[35] A. Nassehi, S. T. Newman, and R. D. Allen, 'The application of multi-agent systems for STEP-NC computer aided process planning of prismatic components', Int. J. Mach. Tools Manuf., vol. 46, no. 5, pp. 559-574, Apr. 2006, doi: 10.1016/j.ijmachtools.2005.06.005.

[36] C. Riaño, E. Rodriguez, and A. J. Alvares, ‘A Closed-Loop Inspection Architecture for Additive Manufacturing Based on STEP Standard', IFAC-Pap., vol. 52, no. 13, pp. 2782-2787, Jan. 2019, doi: 10.1016/j.ifacol.2019.11.629.

[37] Y. Yusofland and K. Case, 'STEP Compliant CAD/CAPP/CAM System for Turning Operations', presented at the Congress on Engineering and Computer Science, Oct. 2008.

[38] X. W. Xu and Q. He, 'Striving for a total integration of CAD, CAPP, CAM and CNC', Robot. Comput.-Integr. Manuf., vol. 20, no. 2, pp. 101-109, Apr. 2004, doi: 10.1016/j.rcim.2003.08.003.

[39] C. Danjou, J. Le Duigou, and B. Eynard, 'Closed-loop Manufacturing, a STEP-NC Process for Data Feedback: A Case Study', Procedia CIRP, vol. 41, pp. 852-857, Jan. 2016, doi: 10.1016/j.procir.2015.12.034. 
[40] F. Zhao, X. Xu, and S. Xie, 'STEP-NC enabled on-line inspection in support of closed-loop machining', Robot. Comput.-Integr. Manuf., vol. 24, no. 2, pp. 200-216, Apr. 2008, doi: 10.1016/j.rcim.2006.10.004.

[41] D. Lofredo, 'Step application protocols overview of Tools'. Steptools inc., 2007. 